\title{
Lusioersily
}

\section{Multi-joint rate of force development testing protocol affects reliability and the smallest detectible difference}

Drake, D., Kennedy, R., \& Wallace, E. S. (2019). Multi-joint rate of force development testing protocol affects reliability and the smallest detectible difference. Journal of Sports Sciences, 37(14), 1570-1581. https://doi.org/10.1080/02640414.2019.1576258

Link to publication record in Ulster University Research Portal

Published in:

Journal of Sports Sciences

Publication Status:

Published (in print/issue): 18/07/2019

DOI:

10.1080/02640414.2019.1576258

\section{Document Version}

Author Accepted version

\section{General rights}

Copyright for the publications made accessible via Ulster University's Research Portal is retained by the author(s) and / or other copyright owners and it is a condition of accessing these publications that users recognise and abide by the legal requirements associated with these rights.

\section{Take down policy}

The Research Portal is Ulster University's institutional repository that provides access to Ulster's research outputs. Every effort has been made to ensure that content in the Research Portal does not infringe any person's rights, or applicable UK laws. If you discover content in the Research Portal that you believe breaches copyright or violates any law, please contact pure-support@ulster.ac.uk. 
1 Manuscript Title: Multi-joint rate of force development testing protocol affects reliability and

2 the smallest detectible difference

3 Running Title: Reliability of isometric RFD

4 Keywords: explosive force; maximal strength; stability reliability; neuromuscular

5 Word Count: 4573

6

7 Authors: David Drake ${ }^{1,2^{*}}$, Rodney A. Kennedy ${ }^{1,3}$ and Eric S. Wallace ${ }^{1,3}$

8 Department/Institution: ${ }^{1}$ School of Sport, Ulster University; ${ }^{2}$ Ulster Rugby, Irish Rugby

9 Football Union; ${ }^{3}$ Sport and Exercise Science Research Institute, Ulster University

10 Corresponding Author Details*: School of Sport, Ulster University, Jordanstown, Shore

11 Road, Newtownabbey, Co. Antrim, BT37 0QB, N. Ireland.

12 Email: daviddrake87@,gmail.com

13 Phone: +447442495722

14 Twitter:@d_drakey

15 ORCID: orcid.org/0000-0003-0440-7097

18 Postal address (all authors): As per corresponding author.

19 Dr Rodney Kennedy: email r.kennedy@ulster.ac.uk; phone +44 2890366242

20 Prof Eric Wallace: email es.wallace@ulster.ac.uk; phone +44 2890366535

23 Disclosure Statement: No external financial support was received for the completion of this 24 study. The authors report no conflicts of interest.

\section{Abstract}


29 Isometric tests have been used to assess rate of force development (RFD), however variation

30 in testing methodologies are known to effect performance outcomes. The aim of this study was

31 to assess the RFD in the isometric squat (ISqT) using two test protocols and two testing angles.

32 Eleven participants (age: $26.8 \pm 4.5$ years, strength training experience: $7.1 \pm 3.03$ years)

33 completed test and retest sessions one week apart, whereby two test protocols with respect to 34 duration and instructions were compared. Isometric peak force (ISqT ${ }^{\text {peak}}$ ) and isometric

\section{Introduction}

Keywords: explosive force; maximal strength; stability reliability; neuromuscular

explosive force (ISqT ${ }^{\exp }$ ) tests were assessed at two joint angles (knee flexion angle $100^{\circ}$ and $125^{\circ}$ ). Force-time traces were sampled and subsequently analysed for RFD measures. Average and instantaneous RFD variables did not meet reliability minimum criteria in $\mathrm{ISqT}^{\text {peak }}$ at $100^{\circ}$ or $125^{\circ}$. The $\mathrm{ISqT}^{\exp }$ test at $100^{\circ}$ met reliability criteria in the RFD $0-200$ and $0-250 \mathrm{~ms}$ variables. The ISqT ${ }^{\exp }$ test at $125^{\circ}$ met reliability criteria in the RFD 0-150, 0-200 and 0-250ms variables. Force-time characteristics were optimized at the higher knee joint angle. This study provides new insights into the reliability of RFD testing. Average and instantaneous RFD measures obtained using a traditional peak force test do not meet basic reliability criteria. Researchers assessing multi-joint RFD should employ the explosive RFD test protocol as opposed to the traditional isometric peak force. 

explosive actions are critical to performance outcomes. Therefore, it's important to test force capacity under these conditions if researchers and coaches are to make practical decisions from assessment (Tillin, Pain, \& Folland, 2013). Rate of force development (RFD) is a mechanical quantity describing the rate of a muscle-tendon contraction (Andersen, Andersen, Zebis, \& Aagaard, 2010; Maffiuletti et al., 2016). Compared to isometric peak force, RFD is more strongly related to sports performance actions and activities of daily living (Maffiuletti, Bizzini, Widler, \& Munzinger, 2010; Tillin et al., 2013). RFD is also more responsive in detecting acute and chronic adaptations in neuromuscular function (Crameri et al., 2007; Hornsby et al., 2017) and has been used as an indirect biological marker of acute structural damage to muscle tissue resulting from exercise (Jenkins et al., 2014; Penailillo, Blazevich, Numazawa, \& Nosaka, 2015).

RFD during isometric contraction is calculated from the slope of the force-time trace (Kawamori et al., 2006; Tillin et al., 2013). Variation in methodological approaches to calculating RFD kinetics include average RFD, instantaneous RFD, and RFD using a range of preset epochs (Haff, Ruben, Lider, Twine, \& Cormie, 2015) and can be described as early or late in terms of the time from contraction onset (Andersen et al., 2010). The reliability of RFD measures is also affected by the chosen variables of interest (Brady, Harrison, Flanagan, Haff, \& Comyns, 2017; Dos'Santos et al., 2016; Haff et al., 2015). With respect to isometric testing, generally it is accepted that RFD is a less reliable measure than peak force during maximal voluntary contractions or peak force tests (Maffiuletti et al., 2016). Specifically, RFD assessed early in the force-time trace (within the first $150 \mathrm{~ms}$ from contraction onset) has shown poor reliability in terms of absolute and relative reliability (Palmer, Pineda, \& Durham, 2017; Prieske, Wick, \& Granacher, 2014). 
79 Work by Maffiuletti et al. (2016) detailed factors effecting isometric testing that require careful consideration such as testing angle and instruction. The appropriate implementation and analysis of RFD measures is critical to obtain both reliable and valid assessments of neuromuscular capacity (Dos'Santos, Lake, Jones, \& Comfort, 2018). However, few studies have addressed the factors outlined by Halperin, Williams, Martin, and Chapman (2016); Maffiuletti et al. (2016); Rodríguez-Rosell, Pareja-Blanco, Aagaard, and González-Badillo (2018) with respect to isometric multi-joint tests. Existing literature assessing the reliability of RFD measures can be categorized as within session reliability (also termed internal consistency or between trial reliability) and stability reliability investigations (also termed test-retest or between session reliability). Stability reliability designs with appropriate time period between tests have greater ecological validity given the reliability statistics represent a time period more akin to the normal variance in assessing athletes in the field of sports science (Taylor, Cronin, Gill, Chapman, \& Sheppard, 2010). As such, the absolute error measured in stability reliability accounts for inherent biological variation and random error of participants (Atkinson \& Nevill, 1998; Hopkins, 2000). In simplistic terms the smaller the absolute error in stability reliability design, the better the measure (Hopkins, 2000). Surprisingly, stability reliability investigations are scarce within isometric multi-joint testing research investigating RFD (Comfort, Jones, McMahon, \& Newton, 2015; Dos'Santos, Thomas, Jones, McMahon, \& Comfort, 2017; Drake, Kennedy, \& Wallace, 2017). Presumably this study design is implemented less frequently in sports science research as its less practical and time efficient to do so compared to within session reliability designs. Furthermore, measurement of the absolute error enables the calculation of the smallest detectible difference (Drake, Kennedy, \& Wallace, 2018). Beyond this threshold, practical inferences can be made that measures in a population are 'true' changes beyond the error of the test. 
104 Reliable testing equipment and protocols are needed to accurately determine responsiveness in 105 isometric performance (Prieske et al., 2014). Based on the instructions provided, isometric contractions can be performed with two different goals: (1) to produce force as quickly as possible and maintain this force application to reach a maximal force output, (2) produce force as fast as possible, categorized as explosive contractions (Duchateau \& Baudry, 2014; Tillin et al., 2013). Results comparing these types of isometric contractions have reported RFD to be 16\% higher for the explosive protocol (Duchateau \& Baudry, 2014). However, such contrasts have not been shown in isometric multi-joint tests. Multi-joint RFD tests have predominantly been implemented with the aim to produce a maximum peak force (evidenced in the duration of trial), with analyses of RFD characteristics occurring from the resultant force-time traces (Brady et al., 2017; Dos'Santos et al., 2017; Haff et al., 2015). Subsequently, we define this approach as the traditional isometric multi-joint peak force test. This traditional approach to instruction and duration is known to result in lower RFD values when using isometric tests (Holtermann, Roeleveld, Vereijken, \& Ettema, 2007; Sahaly, Vandewalle, Driss, \& Monod, 2001). Further investigation of testing protocols such as contraction durations and specific instruction as discussed above are required in isometric multi-joint tests. The primary aim of this study was to assess reliability of force-time characteristics of the isometric squat test (ISqT) using a traditional peak force protocol and an explosive force test protocol. Secondly, this study aimed to assess reliability characteristics at two knee flexion angles, 100 and $125^{\circ}$. Lastly this study aimed to provide normative smallest detectible difference thresholds for RFD measures using the ISqT test.

\section{Methods}

\section{Participants}

128 Eight male and three female participants volunteered to take part in this study (age: $26.8 \pm 4.5$ 
129 years, height: $1.77 \pm 9.8 \mathrm{~m}$, mass: $83.4 \pm 9.3 \mathrm{~kg}$, strength training experience: $7.1 \pm 3.03$ years).

130 Participant inclusion criteria was set as requiring at least two years' strength training experience and be familiar with maximal strength testing. Ethical approval was provided by the University institutional review board (Ulster University). Prior to study commencement, all participants provided written informed consent. Procedures used within this investigation conformed to the Declaration of Helsinki.

\section{Procedures}

137 Testing sessions were standardized to a set time of the day for each participant to maintain 138 consistency of circadian rhythmicity (Teo, McGuigan, \& Newton, 2011). Participants were 139 instructed to maintain their normal physical activity level and nutritional habits throughout the 140 duration of the study. Participants were not permitted to undertake any strength, plyometric or 141 speed training or take any ergogenic supplement throughout involvement in this study. This 142 study assessed the stability reliability of isometric force-time characteristics. Two testing 143 sessions (test and retest) took place one week apart, whereby participants completed isometric 144 squat peak force (ISqT ${ }^{\text {peak }}$ ) and isometric squat explosive force (ISqT ${ }^{\text {exp }}$ ) tests at two relative 145 joint angles (knee flexion angle $100^{\circ}$ and $125^{\circ}$ ). The two test protocols were utilized with the 146 known influence of instruction and the goal on the test on the measurement outcome 147 (Holtermann et al., 2007; Sahaly et al., 2001). Within testing sessions participants completed $148 \mathrm{ISqT}^{\text {peak }}$ and $\mathrm{ISqT}^{\mathrm{exp}}$ at $100^{\circ}$, then completed $\mathrm{ISqT}^{\text {peak }}$ and $\mathrm{ISqT}^{\mathrm{exp}}$ at $125^{\circ}$. Prior to reliability 149 assessments, participants undertook two familiarisation sessions following the specific testing 150 procedures outlined below. Familiarisation sessions were used to stabilize learning effects 151 associated with multi-joint isometric testing (Drake et al., 2018). 
153 A standardized warm-up comprising three minutes of easy jogging followed by dynamic squatting and lunging movements was undertaken by all participants before the specific isometric warm up began. Participants then completed warm-up repetitions of the isometric squat at self-determined estimated $75 \%$ and $90 \%$ of maximal effort prior to beginning testing at the $100^{\circ}$ angle. ISqT was assessed using a custom isometric rack (Samson Equipment Inc, NM, USA) anchored to the floor with adjustable settings to the nearest $2.5 \mathrm{~cm}$ of vertical displacement. The isometric rack was situated over two force plates (Kistler type 9286BA, Winterthur, Switzerland) connected to an analogue to digital converter (Kistler type 5691A1, Winterthur, Switzerland). Temporal and vertical ground reaction force $\left(F_{\mathrm{z}}\right)$ data were collected at a sampling frequency of $1000 \mathrm{~Hz}$ using Bioware ${ }^{\circledR}$ software (Version 5.1, Type 2812A). The force plates were zeroed whilst the participant was standing still with hands on their hips. As such, zero force was defined as the participants' bodyweight. Participants stood on the force plate with their feet approximately shoulder width apart, trunk near-vertical, with the immoveable bar placed above the posterior deltoids at the base of the neck and placed within the isometric rack. Participants relative testing positions were established before each trial, with the knee and hip joint angle confirmed using goniometry (66fit Ltd Lincolnshire, UK). Hip joint angle corresponding to the $100^{\circ}$ knee flexion angle was $148 \pm 3^{\circ}$ and $125^{\circ}$ knee flexion angle was $160 \pm 3^{\circ}$. Participants' stance widths were monitored for consistency between trials. Using a TV screen mounted directly in front of the isometric rack, participants viewed the 'real time' force time trace, enabling participants to self-select the contraction onset by visual inspection of the steady baseline period. Each sampled raw force signal was visually inspected to confirm a steady baseline. Trials not satisfying this condition were excluded and repeated.

The ISqT ${ }^{\text {peak }}$ test was used with the primary goal to produce the highest force possible. Participants were informed that contraction duration would be three seconds. This is the typical 
178 duration used in isometric multi-joint tests with this goal (Drake et al., 2017). Participants

179 maintained a minimal and steady baseline force for 1 second prior to maximal contraction using

180 the visual feedback from the force-time trace on the TV screen, this procedure was repeated in 181 the ISqT ${ }^{\text {exp }}$ test. Participants were instructed to "push against the bar as hard and as fast as 182 possible" for three seconds. This focus of attention has been reported to optimize peak force 183 output (Halperin et al., 2016). Two trials were completed at each joint angle, with two minutes' 184 passive rest between trials.

186 The ISqT ${ }^{\exp }$ test was used with the primary goal to produce the highest force as fast as possible 187 (Sahaly et al., 2001). Participants were instructed to "push against the bar as fast and as hard 188 as possible" for one second. Three trials were completed at each joint angle, with two minutes' 189 passive rest between trials. Trials were manually discarded when a countermovement was 190 visibly detected on the force-time trace during the pre-contraction period or the participant 191 deemed that the trial was not representative of their true maximal explosive effort. 192 Additionally, in the peak force test, trials were discarded if they varied by more than $250 \mathrm{~N}$ 193 from the previous.

\section{Isometric force trace analysis}

Vertical ground reaction force data was smoothed using a moving half-width of $12 \mathrm{~ms}$ (Haff et al., 2015) before being analyzed for specific force-time characteristics using a custom spreadsheet. Contraction onset was determined in similar fashion to the work of (Tillin et al., 2013), using a backwards search of the rate of force-time trace slope. The last instantaneous point where the RFD trace crossed zero was defined as the start on the contraction. The peak force was identified as the highest value on the force-time trace. Time to peak force was calculated as the time from contraction onset to the instantaneous point were peak force was 
measured. Rate of force development was calculated as; $R F D=\frac{\Delta F}{\Delta t}$ and applied to pre-set epochs, $0-30,0-50,0-90,0-100,0-150,0-200$, and $0-250$ milliseconds as well as average RFD between contraction onset and peak force. The highest instantaneous RFD was assessed during 1-millisecond (pRFD1), 2-millisecond (pRFD2), 5-millisecond (pRFD5), 10millisecond, (pRFD10), 20-millisecond (pRFD20), 30-millisecond (pRFD30), and 50millisecond (pRFD50) sampling windows. The variables listed above have been reported in previous studies (Brady et al., 2017; Dos'Santos et al., 2017; Haff et al., 2015). The mean of 210 the two best trials were used for statistical analyses (Dos'Santos et al., 2017) following the 211 removal of sampled trials furthest from the mean (Gathercole, Sporer, Stellingwerff, \& 212 Sleivert, 2015). The best trials were identified in the ISqT ${ }^{\text {peak }}$ test based on the maximum force 213 obtained and for the ISqT ${ }^{\exp }$ test the RFD 0-200ms variable was used in accordance with 214 previous methods (McCaulley et al., 2009).

216 Statistical analysis

217 Prior to analysis, all data were visually inspected for normality. A Shapiro-Wilks test was 218 implemented to assess the normality of the data distribution, and Levene's test used for the 219 assessment of the homogeneity of variance. Stability reliability of RFD measures were 220 evaluated using the following reliability statistics and their associated $90 \%$ confidence 221 intervals; intraclass correlation coefficients (ICC; 3,1), coefficient of variation (CV\%), 222 standard error of measurement (SEM). A paired sample $t$ test was used to detect systematic 223 bias between test-retest. Given no consensus standards exist for reliability measurements in 224 sports science (Atkinson \& Nevill, 1998), we opted for conventional thresholds for relative and 225 absolute reliability as follows, ICC $\geq 0.70$ (Morrow \& Jackson, 1993) and CV $\leq 15 \%$ (Haff et 226 al., 2015). To appropriately characterize the reliability statistics a variable was deemed reliable 227 when the $90 \%$ confidence limits were observed within the above thresholds in line with 
recommendations made by Hopkins (2000); Morrow and Jackson (1993). The smallest detectible difference (SDD) was calculated to provide useful normative data in assessing performance change over time, $\boldsymbol{S D D}=1.96 \times \sqrt{2} \times S E M$. The standard error or measurement was calculated as; $\boldsymbol{S E M}=S D \times \sqrt{1}-I C C$. A paired $t$ test was used to compare outcome values between testing angle and testing protocol conditions. Tests of normality were performed using IBM SPSS Statistics 22 software (SPSS Inc., Chicago, IL, USA). A custom excel spreadsheet (Hopkins, 2002) was modified for the calculation of reliability statistics, with $90 \%$ confidence intervals reported for all measures.

\section{Results}

238 Paired $t$ tests showed no systematic bias was present between test and retest time-points for 239 any variable, except for average RFD in $\operatorname{ISqT}^{\exp }$ test at the $100^{\circ}$ angle $(p=0.02)$. The peak 240 force variable met reliability criteria for the $\mathrm{ISqT}^{\text {peak }}$ at $100^{\circ}(\mathrm{ICC}=0.96, \mathrm{CI}=0.88-0.98 ; \mathrm{CV} \%$ $241=2.78, \mathrm{CI}=2.02-4.63)$ and $125^{\circ}(\mathrm{ICC}=0.92, \mathrm{CI}=0.78-0.98 ; \mathrm{CV} \%=4.98, \mathrm{CI}=3.61-8.33)$ 242 but did not in the ISqT ${ }^{\exp }$ test at either $100^{\circ}$ or $125^{\circ}$ angle. Time to peak force did not meet 243 reliability criteria in any test protocol or angle. No average or instantaneous RFD variable met 244 reliability criteria in $\mathrm{ISqT}^{\text {peak }}$ test at $100^{\circ}$ or $125^{\circ}$. The $\mathrm{ISqT}^{\mathrm{exp}}$ test at $100^{\circ}$ met reliability criteria 245 in the RFD 0-200 ( ICC $=0.92, \mathrm{CI}=0.77-0.97 ; \mathrm{CV} \%=7.00, \mathrm{CI}=5.06-11.78)$ and $0-250$ 246 variables $(\mathrm{ICC}=0.94, \mathrm{CI}=0.81-0.98 ; \mathrm{CV} \%=6.18, \mathrm{CI}=4.47-10.36)$. The $\mathrm{ISqT}^{\exp }$ test at $125^{\circ}$ 247 met reliability criteria in the RFD $0-150(\mathrm{ICC}=0.95, \mathrm{CI}=0.85-0.98 ; \mathrm{CV} \%=5.83, \mathrm{CI}=4.22-$ 248 9.77), $0-200(\mathrm{ICC}=0.97, \mathrm{CI}=0.92-0.99 ; \mathrm{CV} \%=4.13, \mathrm{CI}=2.99-6.88)$ and $0-250$ variables $249(\mathrm{ICC}=0.94, \mathrm{CI}=0.82-0.98 ; \mathrm{CV} \%=5.19, \mathrm{CI}=3.76-8.69)$. No instantaneous $\mathrm{RFD}$ variables 250 met reliability criteria in the $\mathrm{ISqT}^{\mathrm{exp}}$ test at $100^{\circ}$ or $125^{\circ}$. Whilst not meeting reliability criteria, 251 the stability reliability of instantaneous RFD variables was consistently better in the ISqT ${ }^{\exp }$ 252 compared to ISqT ${ }^{\text {peak }}$ test. The change in the mean between test-retest, ICC, CV\%, SEM and 
$\mathrm{SDD}, d$ and $p$ values are presented for all variables in tables 1-4. Mean results for each test angle and test protocol are provided in table 5.

Peak force was optimised in the ISqT ${ }^{\text {peak }}$ compared to the $\mathrm{ISqT}^{\exp }$ protocol, and in the $125^{\circ}$ compared to the $100^{\circ}$ angle. Statistical comparisons for the peak force variable are presented in table 6. Outcome values for RFD 200ms was optimised in the ISqT ${ }^{\exp }$ compared to the $\mathrm{ISqT}^{\text {peak }}$ protocol, and in the $125^{\circ}$ compared to the $100^{\circ}$ angle. Statistical comparisons for the for RFD 200ms variable are presented in table 7.

\section{Discussion}

This study provides new insights into the reliability of multi-joint RFD testing. The primary finding being the reliability of RFD variables obtained using force-time data can be enhanced by subtle amendments to instruction and duration of test protocol. Isometric multi-joint RFD testing has traditionally used a peak force test protocol (also termed maximum voluntary contraction) over a 3 to 5 seconds' contraction duration (Alegre, Jiménez, Gonzalo-Orden, Martín-Acero, \& Aguado, 2006; Comfort et al., 2015; Cormie, Deane, Triplett, \& McBride, 2006; Dos'Santos et al., 2016; Dos'Santos et al., 2017; Haff et al., 2015; Leary et al., 2012; McGuigan, Newton, Winchester, \& Nelson, 2010; McGuigan, Winchester, \& Erickson, 2006; Thomas, Comfort, Chiang, \& Jones, 2015; Thomas, Jones, Rothwell, Chiang, \& Comfort, 2015). We offer evidence that the reliability of RFD is best assessed using an explosive protocol (detailed in methods section). Adopting this protocol enhances the reliability of common RFD measures in comparison to the isometric peak force test (see tables 1, 2, 3 and 4). We contend that several RFD measures demonstrate good relative and absolute reliability in the explosive force test. This finding is promising given the low participant numbers within our study effects the precision of the confidence intervals of measures (Baumgartner \& Chung, 
2001; Morrow \& Jackson, 1993). As such we recommend the explosive force protocol be

279 adopted in future investigations of RFD using isometric multi-joint tests.

280 An abundance of literature reports multi-joint RFD measures to be reliable (Comfort et al., 281 2015; Dos'Santos et al., 2016; Dos'Santos et al., 2017; Haff et al., 2015; Palmer et al., 2017; 282 Thomas, Comfort, et al., 2015; Thomas, Jones, et al., 2015). For comparison between previous 283 studies and our findings, we will discuss the absolute reliability of these studies assessing 284 multi-joint RFD using the confidence intervals of the coefficient of variation statistic (Hopkins, 285 2000). In examination of reliability studies, measures of instantaneous RFD can be observed 286 as having CI between 12 to $21 \%$ (Thomas, Jones, et al., 2015) and 8 to $17 \%$ (Thomas, Comfort, 287 et al., 2015). Studies by Brady et al. (2017); Haff et al. (2015) present CI for a range of average 288 and instantaneous RFD measures which extend beyond the acceptable thresholds set within 289 their study and outside the thresholds set in our study. These studies conducted reliability 290 assessments using between trials design, which is a limitation in terms of their usefulness. 291 Stability reliability assessment are scarce within the published literature to date. In a study by 292 Dos'Santos et al. (2017) showed the stability reliability statistics for average RFD 150ms had 293 CI ranging from 6 to 21\%. Other studies assessing stability reliability include (Comfort et al., 294 2015; Palmer et al., 2017), but these studies did not present CI thus inhibiting comparisons. In 295 stating the CI of RFD measures of the studies above, at best the reliability of RFD measures 296 using the traditional isometric peak force test could be described as questionable. Authors rely 297 on presenting their sample mean $\mathrm{CV}$ as being within their pre-determined threshold for 298 acceptable reliability. This method does not reflect the error across the sample of participants 299 but only for the 'average participant' (Atkinson \& Nevill, 1998). Given a proportion of 300 participant's individual reliability data will lie well outside the pre-determined 'acceptable 301 reliability' thresholds. It is therefore important to characterize the true reliability as the 302 confidence intervals of the error (Hopkins, 2000; Morrow \& Jackson, 1993). Within this study, 
our findings show (CI of RFD measures) average and instantaneous RFD measures obtained using a traditional isometric peak force test do not meet basic reliability criteria (CI within ICC $\geq 0.70$ and $\mathrm{CV} \leq 15 \%$ thresholds). With awareness that no one statistic can demonstrate conclusiveness, it's important to provide a comprehensive approach to the assessment of reliability measures to give a 'true' picture (Bruton, Conway, \& Holgate, 2000). We do not intend to present a case that any one study is reliable or not, but that issues around overall reliability of RFD measures is prevalent within existing evidence. Enhancing reliability of measures can be achieved through a rigorous approach to methodology (Maffiuletti et al., 2016) and will likely result in more informed decision making. Our study shows by amending isometric multi-joint test protocol to an explosive RFD test improves reliability of the key measures and therefore enhances their application in practice.

315 Whilst a multitude of variables have been assessed in multi-joint RFD tests (Brady et al., 2017; 316 Dos'Santos et al., 2016; Haff et al., 2015; Palmer et al., 2017), it is common that researchers 317 will decide to use a limited number of variables within their investigations for practical reasons. 318 As such specific knowledge on the most reliable variables is required. This study provides new 319 information by comparing the reliability of multi-joint RFD variables using an explosive 320 isometric test. Average RFD measures $<150 \mathrm{~ms}$ post contraction onset did not meet reliability 321 criteria. Whilst our findings are not directly comparable to other work given our reliability 322 thresholds were more stringent, there is congruence with reports that early RFD variables $323(<150 \mathrm{~ms})$ are less reliable than RFD variables determined later $(>150 \mathrm{~ms})$ in the force-time 324 trace (Brady et al., 2017; Palmer et al., 2017; Prieske et al., 2014). In conjunction with the 325 findings of Haff et al. (2015) we found the average RFD variable did not meet reliability 326 criteria. We suggest this variable is affected by variance in contraction duration and should be 327 avoided as a measure using the protocols implemented in our investigation. Reliability statistics 
for the time to peak force variable within our study across both test protocols and both test angles verify the lack of stability of contraction duration in isometric testing. Average measures over the force time trace undoubtedly provide a more comprehensive analysis of neuromuscular capacity than a single measure (Maffiuletti et al., 2016). Perhaps late RFD variables should be used instead of the overall average RFD variable as they offer greater stability reliability. We also caution the use of early RFD measures given the poor reliability found in both the isometric peak force and explosive force test in this study.

Common use of instantaneous RFD variables (also termed peak or maximum RFD) are present within sports science literature (Alegre et al., 2006; Kawamori et al., 2006; McGuigan et al., 2010; McGuigan et al., 2006; Stone et al., 2004; Stone et al., 2005; Thomas, Comfort, et al., 2015). Contrary to common use of instantaneous RFD variables in research, all instantaneous RFD measures failed to meet reliability within our study. Haff et al. (2015) reported only instantaneous RFD using a 20ms epoch was reliable, having assessed 2,5,10,20,30, and 50ms epochs. Our findings are supported by Brady et al. (2017) who showed no instantaneous measures of RFD to meet reliability criteria having used the same epochs as Haff et al. (2015) within an isometric peak force test. Maffiuletti et al. (2016) explains instantaneous RFD represents single steepest part of the force-time trace and by nature can be an inconsistent point on the force-time trace. Whilst the band-width of the epochs may accommodate the overall reliability, the measure is still inconsistent between trials and participants. Our study repeated the same epochs (Brady et al., 2017; Haff et al., 2015) and found no instantaneous variable to be reliable for the isometric explosive or peak force test. We suggest the application of instantaneous variables may be problematic using existing protocols and further work may be required to explore the function of instantaneous variables in future investigations (Maffiuletti et al., 2016). 
There is considerable debate concerning the appropriate testing angle for isometric multi-joint testing. Whilst certain authors detail the importance of angle on reliability statistics (Dos'Santos et al., 2017; Palmer et al., 2017) alternative findings suggest that test angle has little effect on reliability (Comfort et al., 2015). Principally within our investigation, joint angle had negligible effects on the reliability of isometric force-time measures. However, we note a tendency for the isometric explosive force test at $125^{\circ}$ to have greater relative and absolute reliability for average RFD measures in both the isometric peak force and isometric explosive force test compared to the $100^{\circ}$ angle. Additionally, using the isometric explosive test the RFD $150 \mathrm{~ms}$ variable met the overall reliability criteria for the $125^{\circ}$ but not the $100^{\circ}$ angle. Whilst marginal, these findings are supported by the position related increases in the reliability of isometric squats as knee flexion angle decreases in the work of Palmer et al. (2017). Rationale for this tendency is not clear, but a potential explanation for lower testing positions (higher knee and hip flexion) having marginally less reliability may be due to the greater relative muscular effort (Bryanton, Kennedy, Carey, \& Chiu, 2012; Palmer et al., 2017) which in turn causes greater variation in early RFD. Given no consensus can be determined for the best isometric multijoint testing test angle (Dos'Santos et al., 2017), we contend that arguments for the specificity of training stimulus (Balshaw, Massey, Maden-Wilkinson, Tillin, \& Folland, 2016; Folland \& Williams, 2007; Tillin \& Folland, 2014) be considered similarly to isometric testing methodology in terms of selection of the most appropriate testing angle and protocol. For example, the study by Beckham (2012) evaluated isometric strength across a range of positions specific to participants sporting demands. This type of approach, i.e. specificity of testing angle may enhance the ability of isometric tests to detect training adaptations. 
377 As discussed within the methodological review by Rodríguez-Rosell et al. (2018), it is often recommended that joint angles during isometric testing should be the position that optimises the mechanical output of force characteristics. Our findings confirm that peak force is optimised at the $125^{\circ}$ knee joint angle using the isometric peak force test (see table 6). RFD $200 \mathrm{~ms}$ values are optimised using the explosive force test comparatively to the peak force test with findings also confirming higher values at the higher angle (table 7). Taken together, we provide evidence for isometric testing at higher knee joint angles. However, we add an important finding that if testing is to be conducted under the conditions that optimise outcome variables then RFD should be assessed using the explosive force protocol implemented in this study, whereas peak force should be assessed using the traditional peak force protocol.

With appropriate stability reliability study designs, test data can be used as normative for the investigated population. For a test to be deemed useful, the smallest detectible difference should be calculated to evaluate responsiveness of training interventions in studies with comparable populations (Drake et al., 2018). Acute and chronic responses of individuals or groups beyond the SDD can thus be monitored, with changes being attributed to fatigue or adaptation rather than error in testing methodology (Dos'Santos et al., 2017; Prieske et al., 2014). The usefulness of previous work is limited by the fact that the study design assesses only between trial variation (Brady et al., 2017; Haff et al., 2015). This study provides new SDD data for the isometric explosive force test which can now be used to assess adaptation to training with comparable populations. Specific SDD for all force-time variables are provided within tables ( 1 and 2 for isometric peak force test at $100^{\circ}$ and $125^{\circ}$ respectively, 3 and 4 for isometric explosive force test at $100^{\circ}$ and $125^{\circ}$ respectively). 
In summary, evidence from our study demonstrates enhanced reliability when assessing RFD using the isometric explosive force test compared to the traditional isometric peak force test. Principally average RFD over 150, 200 and 250ms demonstrate best reliability when using the isometric explosive force test and are recommended variables when assessing RFD. Testing angle had limited effect on reliability statistics, subsequently testing angle may be a factor more relevant to specificity in detecting adaptation as opposed to reliability investigations. Higher testing angles optimized both peak force and RFD outcomes and therefore should be considered the most appropriate angle to conduct isometric squat tests. Finally, the SDD of RFD measures provided within this study are a useful point from which responsiveness may be determined in future studies assessing RFD.

\section{References}

Alegre, L. M., Jiménez, F., Gonzalo-Orden, J. M., Martín-Acero, R., \& Aguado, X. (2006). Effects of dynamic resistance training on fascicle length and isometric strength. Journal of Sports Sciences, 24(5), 501-508.

Andersen, L. L., Andersen, J. L., Zebis, M. K., \& Aagaard, P. (2010). Early and late rate of force development: differential adaptive responses to resistance training? Scand J Med Sci Sports, 20, e162-e169.

Atkinson, G., \& Nevill, A. M. (1998). Statistical methods for assessing measurement error (reliability) in variables relevant to sports medicine. Sports Medicine, 26(4), 217-238.

Balshaw, T. G., Massey, G. J., Maden-Wilkinson, T. M., Tillin, N. A., \& Folland, J. P. (2016). Training specific functional, neural and hypertrophic adaptations to explosivevs. sustained-contraction strength training. J. Appl Physiol, 120(11), 1364-1373.

Baumgartner, T. A., \& Chung, H. (2001). Confidence limits for intraclass reliability coefficients. Measure Physical Education and Exercise Science, 5(3), 179-188. 
Beckham, G., Lamont, H.S., Sato, K., Ramsey, M.W., Haff, G., Stone, M. (2012). Isometric strength of powerlifters in key positions of the conventional deadlift. Journal of Trainology, 1(2), 32-35.

Brady, C. J., Harrison, A. J., Flanagan, E. P., Haff, G. G., \& Comyns, T. M. (2017). A Comparison of the Isometric Mid-Thigh Pull and Isometric Squat: Intraday Reliability, Usefulness and the Magnitude of Difference Between Tests. Int, J. Sports Physiol Perform, 13(7), 844-852.

Bruton, A., Conway, J. H., \& Holgate, S. T. (2000). Reliability: What is it, and how is it measured? Physiotherapy, 86(2), 94-99.

Bryanton, M. A., Kennedy, M. D., Carey, J. P., \& Chiu, L. Z. F. (2012). Effect of squat depth and barbell load on relative muscular effort in squatting. Journal of Strength and Conditioning Research, 26(10), 2820-2828.

Comfort, P., Jones, P. A., McMahon, J. J., \& Newton, R. (2015). Effect of knee and trunk angle on kinetic variables during the isometric midthigh pull: test-retest reliability. Int J Sports Physiol Perform, 10(1), 58-63.

Cormie, P., Deane, R. S., Triplett, N. T., \& McBride, J. M. (2006). Acute effects of wholebody vibration on muscle activity, strength, and power. Journal of Strength and Conditioning Research, 20(2), 257-261.

Crameri, R. M., Aagaard, P., Qvortrup, K., Langberg, H., Olesen, J., \& Kjær, M. (2007). Myofibre damage in human skeletal muscle: effects of electrical stimulation versus voluntary contraction. The Journal of Physiology, 583(1), 365-380.

Dos'Santos, T., Jones, P. A., Kelly, J., McMahon, J. J., Comfort, P., \& Thomas, C. (2016). Effect of sampling frequency on isometric mid-thigh pull kinetics. Int J Sports Physiol Perform, 11(2), 255-260. 
Dos'Santos, T., Lake, J., Jones, P., \& Comfort, P. (2018). Effect of Low-Pass Filtering on Isometric Mid-Thigh Pull Kinetics. Journal of Strength and Conditioning Research, 32(4), 983-989.

Dos'Santos, T., Thomas, C., Jones, P. A., McMahon, J. J., \& Comfort, P. (2017). The effect of hip joint angle on isometric midthigh pull kinetics. J. Strength Cond Res, 31(10), $2748-2757$.

Drake, D., Kennedy, R., \& Wallace, E. (2017). The validity and responsiveness of isometric lower body multi-joint tests of muscular strength: a systematic review. Sports Medicine - Open, 3(1), 23.

Drake, D., Kennedy, R., \& Wallace, E. (2018). Familiarization, validity and smallest detectable difference of the isometric squat test in evaluating maximal strength. Journal of Sports Sciences, 36(18), 2087-2095.

Duchateau, J., \& Baudry, S. (2014). Maximal discharge rate of motor units determines the maximal rate of force development during ballistic contractions in human. Frontiers in Human Neuroscience, 8, 234.

Folland, J. P., \& Williams, A. G. (2007). Morphological and neurological contributions to increased strength. Sports Medicine, 37(2), 145-168.

Gathercole, R., Sporer, B., Stellingwerff, T., \& Sleivert, G. (2015). Alternative countermovement-jump analysis to quantify acute neuromuscular fatigue. International Journal of Sports Physiology and Performance, 10(1), 84-92.

Haff, G. G., Ruben, R. P., Lider, J., Twine, C., \& Cormie, P. (2015). A comparison of methods for determining the rate of force development during isometric midthigh clean pulls. Journal of strength and conditioning research, 29(2), 386-395. 
Halperin, I., Williams, K. J., Martin, D. T., \& Chapman, D. W. (2016). The effects of attentional focusing instructions on force production during the isometric midthigh pull. Journal of Strength and Conditioning Research, 30(4), 919-923.

Holtermann, A., Roeleveld, K., Vereijken, B., \& Ettema, G. (2007). The effect of rate of force development on maximal force production: acute and training-related aspects. European Journal of Applied Physiology, 99(6), 605-613.

Hopkins, W. G. (2000). Measures of reliability in sports medicine and science. Sports Medicine, 30(1), 1-15.

Hopkins, W. G. (2002). A new view of statistics [Online]. Retrieved from:

http://sportsci.org/resource/stats/effectmag.html.

Hornsby, W. G., Gentles, J. A., MacDonald, C. J., Mizuguchi, S., Ramsey, M. W., \& Stone, M. H. (2017). Maximum strength, rate of force development, jump height, and peak power alterations in weightlifters across five months of training. Sports, 5(4), 78.

Jenkins, N. D., Housh, T. J., Traylor, D. A., Cochrane, K. C., Bergstrom, H. C., Lewis, R. W., . . Cramer, J. T. (2014). The rate of torque development: a unique, non-invasive indicator of eccentric-induced muscle damage? Int, J. Sports Med, 35(14), 1190-1195

Kawamori, N., Rossi, S. J., Justice, B. D., Haff, E. E., Pistilli, E. E., O'Bryant, H. S., . . Haff, G. G. (2006). Peak force and rate of force development during isometric and dynamic mid-thigh clean pulls performed at various intensities. Journal of Strength and Conditioning Research, 20(3), 483-491.

Leary, B. K., Statler, J., Hopkins, B., Fitzwater, R., Kesling, T., Lyon, J., . . Haff, G. G. (2012). The relationship between isometric force-time curve characteristics and club head speed in recreational golfers. Journal of Strength and Conditioning Research, 26(10), 2685-2697. 
Maffiuletti, N. A., Aagaard, P., Blazevich, A. J., Folland, J., Tillin, N., \& Duchateau, J. (2016). Rate of force development: physiological and methodological considerations. European Journal of Applied Physiology, 1-26.

Maffiuletti, N. A., Bizzini, M., Widler, K., \& Munzinger, U. (2010). Asymmetry in quadriceps rate of force development as a functional outcome measure in TKA. Clin Orthop Relat Res, 468, 191-198.

McCaulley, G. O., McBride, J. M., Cormie, P., Hudson, M. B., Nuzzo, J. L., Quindry, J. C., \& Travis Triplett, N. (2009). Acute hormonal and neuromuscular responses to hypertrophy, strength and power type resistance exercise. European Journal of Applied Physiology, 105(5), 695-704.

McGuigan, M. R., Newton, M. J., Winchester, J. B., \& Nelson, A. G. (2010). Relationship between isometric and dynamic strength in recreationally trained men. Journal of Strength and Conditioning Research, 24(9), 2570-2573.

McGuigan, M. R., Winchester, J. B., \& Erickson, T. (2006). The importance of isometric maximum strength in college wrestlers. Journal of Sports Science and Medicine, 5, 108-113.

Morrow, J. R., \& Jackson, A. w. (1993). How "Significant" is Your Reliability? Research Quarterly for Exercise and Sport, 64(3), 352-355.

Palmer, T. B., Pineda, J. G., \& Durham, R. M. (2017). Effects of Knee Position on the Reliability and Production of Maximal and Rapid Strength Characteristics During an Isometric Squat Test. Journal of Applied Biomechanics, 34(2), 111-117.

Penailillo, L., Blazevich, A., Numazawa, H., \& Nosaka, K. (2015). Rate of force development as a measure of muscle damage. Scand, J. Med Sci Sports, 25(3), 417427. 
Prieske, O., Wick, D., \& Granacher, U. (2014). Intrasession and Intersession Reliability in Maximal and Explosive Isometric Torque Production of the Elbow Flexors. The Journal of Strength \& Conditioning Research, 28(6), 1771-1777.

Rodríguez-Rosell, D., Pareja-Blanco, F., Aagaard, P., \& González-Badillo, J. J. (2018).

Physiological and methodological aspects of rate of force development assessment in human skeletal muscle. Clinical physiology and functional imaging, Advance online publication. Clinical physiology and functional imaging. 38(5), 743-762.

Sahaly, R., Vandewalle, H., Driss, T., \& Monod, H. (2001). Maximal voluntary force and rate of force development in humans - importance of instruction. Eur J Appl Physiol, $85(3-4), 345-350$.

Stone, M. H., Sands, W. A., Carlock, J., Callan, S., Dickie, D., Daigle, K., . . Hartman, M. (2004). The importance of isometric maximum strength and peak rate of force development in sprint cycling. Journal of Strength and Conditioning Research, 18(4), 878-884.

Stone, M. H., Sands, W. A., Pierce, K. C., Carlock, J., Cardinale, M., \& Newton, R. U. (2005). Relationship of maximum strength to weightlifting performance. Med Sci Sports Exerc, 37(6), 1037-1043.

538 Taylor, K.-L., Cronin, J., Gill, N. D., Chapman, D. W., \& Sheppard, J. (2010). Sources of $539 \quad$ Variability in Iso-Inertial Jump Assessments. International Journal of Sports $540 \quad$ Physiology \& Performance, 5(4), 546-558.

541 Teo, W. P., McGuigan, M. R., \& Newton, M. J. (2011). The effects of circadian rhythmicity of salivary cortisol and testosterone on maximal isometric force, maximal dynamic force, and power output. . Journal of Strength and Conditioning Research, 25(6), $1538-1545$. 
545 Thomas, C., Comfort, P., Chiang, C., \& Jones, P. A. (2015). Relationship between isometric

mid thigh pull variables and sprint and change of direction performance in collegiate athletes. Journal of Trainology, 4(1), 6-10.

548 Thomas, C., Jones, P. A., Rothwell, J., Chiang, C. Y., \& Comfort, P. (2015). An investigation into the relationship between maximum isometric strength and vertical jump performance. Journal of Strength and Conditioning Research, 29(8), 2176-2185.

Tillin, N. A., \& Folland, J. P. (2014). Maximal and explosive strength training elicit distinct neuromuscular adaptations, specific to the training stimulus. European Journal of Applied Physiology, 114(2), 365-374.

554 Tillin, N. A., Pain, M. T. G., \& Folland, J. (2013). Explosive force production during 555 isometric squats correlates with athletic performance in rugby union players. Journal 556 of Sports Sciences, 31(1), 66-76. 
Table 1. Reliability statistics for $\mathrm{ISqT}^{\text {peak }}$ test at $100^{\circ} \mathrm{knee}$ flexion

\begin{tabular}{|c|c|c|c|c|c|c|c|}
\hline & $\begin{array}{c}\text { Change in } \\
\text { mean } \\
(90 \% \mathrm{CI})\end{array}$ & $\begin{array}{c}\text { ICC } \\
(90 \% \mathrm{CI})\end{array}$ & $\begin{array}{c}\text { CV\% } \\
(90 \% \mathrm{CI})\end{array}$ & $\begin{array}{c}\text { SEM } \\
(90 \% \mathrm{CI})\end{array}$ & SDD & $d$ & $p$ \\
\hline Peak Force & $\begin{array}{c}3.39 \\
(-42.67 \\
49.44)\end{array}$ & $\begin{array}{c}0.96 \\
(0.89, \\
0.99)\end{array}$ & $\begin{array}{c}2.79 \\
(2.03,4.63)\end{array}$ & $\begin{array}{c}48.15 \\
(28.91 \\
67.38)\end{array}$ & 133.5 & 0.01 & 0.90 \\
\hline TTPF & $\begin{array}{c}0.11 \\
(-0.17,0.38)\end{array}$ & $\begin{array}{c}0.44 \\
(-0.10 \\
0.78)\end{array}$ & $\begin{array}{c}22.27 \\
(15.80 \\
39.21)\end{array}$ & $\begin{array}{c}0.32 \\
(-1.25 \\
1.89)\end{array}$ & 0.89 & 0.39 & 0.50 \\
\hline RFD 0-30ms & $\begin{array}{c}-60.14 \\
(-378.2 \\
257.9) \\
-243.6\end{array}$ & $\begin{array}{c}0.52 \\
(0.00 \\
0.82) \\
0.38\end{array}$ & $\begin{array}{c}43.71 \\
(30.28 \\
81.59) \\
67.34\end{array}$ & $\begin{array}{c}366.9 \\
(313.8, \\
420.0) \\
739.7\end{array}$ & 1017 & -0.17 & 0.74 \\
\hline RFD $0-50 \mathrm{~ms}$ & $\begin{array}{c}(-870.4 \\
383.1)\end{array}$ & $\begin{array}{c}(-0.18 \\
0.75)\end{array}$ & $\begin{array}{c}(45.58, \\
133.3)\end{array}$ & $\begin{array}{l}(664.3, \\
815.1)\end{array}$ & 2050 & -0.45 & 0.49 \\
\hline RFD 0-90ms & $\begin{array}{c}-495.4 \\
(-1726 \\
735.2)\end{array}$ & $\begin{array}{c}0.20 \\
(-0.36 \\
0.65)\end{array}$ & $\begin{array}{c}89.14 \\
(59.18 \\
185.3)\end{array}$ & $\begin{array}{r}1479 \\
(1372, \\
1586)\end{array}$ & 4100 & -0.72 & 0.48 \\
\hline $\begin{array}{l}\text { RFD 0- } \\
100 \mathrm{~ms}\end{array}$ & $\begin{array}{c}-518.7 \\
(-1803 \\
765.8)\end{array}$ & $\begin{array}{c}0.18 \\
(-0.37 \\
0.64)\end{array}$ & $\begin{array}{c}86.49 \\
(57.55 \\
178.8)\end{array}$ & $\begin{array}{l}1545 \\
(1436, \\
1654)\end{array}$ & 4284 & -0.75 & 0.48 \\
\hline $\begin{array}{c}\text { RFD 0- } \\
150 \mathrm{~ms}\end{array}$ & $\begin{array}{c}-509.4 \\
(-1748 \\
729.1)\end{array}$ & $\begin{array}{c}0.25 \\
(-0.31, \\
0.68)\end{array}$ & $\begin{array}{c}63.09 \\
(42.87 \\
123.6)\end{array}$ & $\begin{array}{c}1482 \\
(1375, \\
1588)\end{array}$ & 4107 & -0.64 & 0.47 \\
\hline $\begin{array}{l}\text { RFD 0- } \\
200 \mathrm{~ms}\end{array}$ & $\begin{array}{c}-390.5 \\
(-1391 \\
610.1)\end{array}$ & $\begin{array}{c}0.39 \\
(-0.16 \\
0.76)\end{array}$ & $\begin{array}{c}41.12 \\
(28.56 \\
76.24)\end{array}$ & $\begin{array}{l}1174 \\
(1079, \\
1269)\end{array}$ & 3255 & -0.44 & 0.49 \\
\hline $\begin{array}{l}\text { RFD 0- } \\
250 \mathrm{~ms}\end{array}$ & $\begin{array}{c}-305.9 \\
(-966.7 \\
354.8)\end{array}$ & $\begin{array}{c}0.63 \\
(0.17, \\
0.87)\end{array}$ & $\begin{array}{c}25.21 \\
(17.82 \\
44.77)\end{array}$ & $\begin{array}{c}747.4 \\
(671.6 \\
823.2)\end{array}$ & 2072 & -0.32 & 0.42 \\
\hline $\begin{array}{c}\text { Average } \\
\text { RFD }\end{array}$ & $\begin{array}{c}-56.70 \\
(-239.5 \\
126.1)\end{array}$ & $\begin{array}{c}0.62 \\
(0.15 \\
0.86)\end{array}$ & $\begin{array}{c}23.81 \\
(16.86 \\
42.10)\end{array}$ & $\begin{array}{c}208.3 \\
(168.3 \\
248.4)\end{array}$ & 578 & -0.22 & 0.58 \\
\hline pRFD $1 \mathrm{~ms}$ & $\begin{array}{l}-615.5 \\
(-1521 \\
289.6)\end{array}$ & $\begin{array}{c}0.69 \\
(0.26 \\
0.89)\end{array}$ & $\begin{array}{r}16.56 \\
(11.82 \\
28.66)\end{array}$ & $\begin{array}{c}1019 \\
(930.8 \\
1108)\end{array}$ & 2825 & -0.43 & 0.24 \\
\hline pRFD $2 \mathrm{~ms}$ & $\begin{array}{c}-583.6 \\
(-1493 \\
326.0)\end{array}$ & $\begin{array}{c}0.68 \\
(0.24, \\
0.89)\end{array}$ & $\begin{array}{r}17.30 \\
(12.34 \\
30.02)\end{array}$ & $\begin{array}{c}1025 \\
(936.5 \\
1114)\end{array}$ & 2842 & -0.41 & 0.27 \\
\hline pRFD 5ms & $\begin{array}{c}-527.6 \\
(-1415 \\
360.2)\end{array}$ & $\begin{array}{c}0.69 \\
(0.26, \\
0.89)\end{array}$ & $\begin{array}{c}17.17 \\
(12.25 \\
29.79)\end{array}$ & $\begin{array}{c}998.4 \\
(910.8, \\
1086)\end{array}$ & 2767 & -0.37 & 0.30 \\
\hline pRFD 10ms & $\begin{array}{c}-560.5 \\
(-1456 \\
334.9)\end{array}$ & $\begin{array}{c}0.68 \\
(0.24, \\
0.89)\end{array}$ & $\begin{array}{c}17.60 \\
(12.55 \\
30.56)\end{array}$ & $\begin{array}{c}1009 \\
(921.0 \\
1097)\end{array}$ & 2797 & -0.40 & 0.28 \\
\hline pRFD 20ms & $\begin{array}{c}-590.0 \\
(-1472 \\
292.0)\end{array}$ & $\begin{array}{c}0.68 \\
(0.24, \\
0.89)\end{array}$ & $\begin{array}{c}17.81 \\
(12.70 \\
30.95)\end{array}$ & $\begin{array}{c}994.0 \\
(906.6, \\
1081)\end{array}$ & 2755 & -0.43 & 0.25 \\
\hline pRFD 30ms & $\begin{array}{c}-588.1 \\
(-1456 \\
279.4)\end{array}$ & $\begin{array}{c}0.67 \\
(0.24, \\
0.88)\end{array}$ & $\begin{array}{c}17.97 \\
(12.81 \\
31.25)\end{array}$ & $\begin{array}{c}978.3 \\
(891.6, \\
1065)\end{array}$ & 2712 & -0.44 & 0.25 \\
\hline pRFD 50ms & $\begin{array}{c}-590.9 \\
(-1438 \\
256.4)\end{array}$ & $\begin{array}{c}0.65 \\
(0.20, \\
0.88)\end{array}$ & $\begin{array}{c}18.45 \\
(13.14 \\
32.12)\end{array}$ & $\begin{array}{c}959.3 \\
(873.4 \\
1045)\end{array}$ & 2659 & -0.47 & 0.23 \\
\hline
\end{tabular}

Abbreviations: $\mathrm{ICC}=$ intraclass correlation coefficient; $\mathrm{CV} \%=$ coefficient of variation; $\mathrm{SEM}=$ standard error of measurement; $\mathrm{SDD}=$ smallest detectible difference; $\mathrm{CI}=$ confidence interval; TTPF = time to peak force $(\mathrm{ms})$; 
pRFD = instantaneous RFD. Peak force measured in newtons (N), RFD measured in N/s. Numerical values presented after RFD represent pre-set time epochs. 
Table 2. Reliability statistics for ISqT ${ }^{\text {peak }}$ test at $125^{\circ}$ knee flexion

\begin{tabular}{|c|c|c|c|c|c|c|c|}
\hline & $\begin{array}{c}\text { Change in } \\
\text { mean } \\
(90 \% \mathrm{CI})\end{array}$ & $\begin{array}{c}\text { ICC } \\
(90 \% \mathrm{CI})\end{array}$ & $\begin{array}{c}\text { CV\% } \\
(90 \% \mathrm{CI})\end{array}$ & $\begin{array}{c}\text { SEM } \\
(90 \% \mathrm{CI})\end{array}$ & SDD & $d$ & $p$ \\
\hline Peak Force & $\begin{array}{c}-30.14 \\
(-136.8, \\
76.47)\end{array}$ & $\begin{array}{c}0.92 \\
(0.78 \\
0.98)\end{array}$ & $\begin{array}{c}4.98 \\
(3.61,8.33)\end{array}$ & $\begin{array}{l}113.1 \\
(83.6, \\
142.6)\end{array}$ & 313.4 & -0.08 & 0.62 \\
\hline TTPF & $\begin{array}{c}-0.005 \\
(-0.24,0.23)\end{array}$ & $\begin{array}{c}0.07 \\
(-0.47 \\
0.57)\end{array}$ & $\begin{array}{c}15.41 \\
(11.02 \\
26.59)\end{array}$ & $\begin{array}{c}0.29 \\
(-1.20 \\
1.77)\end{array}$ & 0.794 & -0.07 & 0.97 \\
\hline RFD $0-30 \mathrm{~ms}$ & $\begin{array}{c}-499.8 \\
(-1271 \\
271.1) \\
-781.8\end{array}$ & $\begin{array}{c}0.22 \\
(-0.34 \\
0.66) \\
0.34\end{array}$ & $\begin{array}{c}64.27 \\
(43.62, \\
126.27) \\
58.40\end{array}$ & $\begin{array}{c}899.0 \\
(815.9 \\
982.1) \\
1451\end{array}$ & 2492 & -1.10 & 0.27 \\
\hline RFD $0-50 \mathrm{~ms}$ & $\begin{array}{c}(-2065 \\
501.5)\end{array}$ & $\begin{array}{c}(-0.22 \\
0.73)\end{array}$ & $\begin{array}{c}(39.86, \\
113.1)\end{array}$ & $\begin{array}{l}(1346, \\
1557)\end{array}$ & 4023 & -0.77 & 0.29 \\
\hline RFD $0-90 \mathrm{~ms}$ & $\begin{array}{c}-766.9 \\
(-2124 \\
590.7)\end{array}$ & $\begin{array}{c}0.55 \\
(0.05 \\
0.83)\end{array}$ & $\begin{array}{c}38.46 \\
(26.79 \\
70.81)\end{array}$ & $\begin{array}{l}1521 \\
(1413, \\
1630)\end{array}$ & 4217 & -0.46 & 0.33 \\
\hline $\begin{array}{l}\text { RFD 0- } \\
100 \mathrm{~ms}\end{array}$ & $\begin{array}{c}-719.2 \\
(-2004, \\
565.1)\end{array}$ & $\begin{array}{c}0.58 \\
(0.09 \\
0.85)\end{array}$ & $\begin{array}{c}35.44 \\
(24.76 \\
64.72)\end{array}$ & $\begin{array}{l}1439 \\
(1334, \\
1544)\end{array}$ & 3988 & -0.43 & 0.33 \\
\hline $\begin{array}{c}\text { RFD 0- } \\
150 \mathrm{~ms}\end{array}$ & $\begin{array}{c}-695.2 \\
(-1904 \\
513.5)\end{array}$ & $\begin{array}{c}0.61 \\
(0.13 \\
0.86)\end{array}$ & $\begin{array}{c}29.70 \\
(20.89 \\
53.39)\end{array}$ & $\begin{array}{l}1351 \\
(1249, \\
1453)\end{array}$ & 3744 & -0.42 & 0.32 \\
\hline $\begin{array}{l}\text { RFD 0- } \\
200 \mathrm{~ms}\end{array}$ & $\begin{array}{c}-563.2 \\
(-1570 \\
444.0)\end{array}$ & $\begin{array}{l}0.68 \\
(0.25 \\
0.89)\end{array}$ & $\begin{array}{c}25.02 \\
(17.69 \\
44.40)\end{array}$ & $\begin{array}{l}1114 \\
(1022, \\
1207)\end{array}$ & 3088 & -0.35 & 0.33 \\
\hline $\begin{array}{l}\text { RFD 0- } \\
250 \mathrm{~ms}\end{array}$ & $\begin{array}{c}-300.8 \\
(-1036 \\
434.3)\end{array}$ & $\begin{array}{c}0.77 \\
(0.41 \\
0.92)\end{array}$ & $\begin{array}{c}19.91 \\
(14.16, \\
34.81)\end{array}$ & $\begin{array}{c}805 \\
(726,883)\end{array}$ & 2230 & -0.21 & 0.47 \\
\hline $\begin{array}{c}\text { Average } \\
\text { RFD }\end{array}$ & $\begin{array}{l}-19.0 \\
(-174, \\
136.2)\end{array}$ & $\begin{array}{c}0.31 \\
(-0.25 \\
0.72)\end{array}$ & $\begin{array}{c}16.31 \\
(11.65 \\
28.22)\end{array}$ & $\begin{array}{c}184 \\
(146,221)\end{array}$ & 509.3 & -0.16 & 0.83 \\
\hline pRFD $1 \mathrm{~ms}$ & $\begin{array}{c}-1187 \\
(-2957 \\
583.6)\end{array}$ & $\begin{array}{r}0.62 \\
(0.15 \\
0.86)\end{array}$ & $\begin{array}{c}23.32 \\
(16.52 \\
41.17)\end{array}$ & $\begin{array}{l}1955 \\
(1832, \\
2077)\end{array}$ & 5418 & -0.48 & 0.25 \\
\hline pRFD 2ms & $\begin{array}{c}-1148 \\
(-2923, \\
627.8)\end{array}$ & $\begin{array}{c}0.63 \\
(0.16 \\
0.87)\end{array}$ & $\begin{array}{r}24.39 \\
(17.25 \\
43.19)\end{array}$ & $\begin{array}{c}1961 \\
(1838, \\
2083)\end{array}$ & 5435 & -0.46 & 0.27 \\
\hline pRFD 5ms & $\begin{array}{c}-1110 \\
(-2872 \\
652.1)\end{array}$ & $\begin{array}{c}0.64 \\
(0.17, \\
0.87)\end{array}$ & $\begin{array}{c}24.65 \\
(17.43 \\
43.69)\end{array}$ & $\begin{array}{l}1947 \\
(1824, \\
2069)\end{array}$ & 5396 & -0.44 & 0.28 \\
\hline pRFD $10 \mathrm{~ms}$ & $\begin{array}{c}-1127 \\
(-2905 \\
651.7)\end{array}$ & $\begin{array}{c}0.63 \\
(0.16, \\
0.87)\end{array}$ & $\begin{array}{c}25.22 \\
(17.83 \\
44.78)\end{array}$ & $\begin{array}{l}1969 \\
(1846, \\
2092)\end{array}$ & 5457 & -0.45 & 0.28 \\
\hline pRFD $20 \mathrm{~ms}$ & $\begin{array}{c}-1099 \\
(-2828 \\
630.5)\end{array}$ & $\begin{array}{c}0.63 \\
(0.17, \\
0.87)\end{array}$ & $\begin{array}{r}24.96 \\
(17.65 \\
44.29)\end{array}$ & $\begin{array}{l}1916 \\
(1794, \\
2037)\end{array}$ & 5310 & -0.44 & 0.27 \\
\hline pRFD 30ms & $\begin{array}{c}-1029 \\
(-2686 \\
627.8)\end{array}$ & $\begin{array}{c}0.64 \\
(0.18, \\
0.87)\end{array}$ & $\begin{array}{r}24.53 \\
(17.35 \\
43.47)\end{array}$ & $\begin{array}{c}1837 \\
(1719, \\
1956)\end{array}$ & 5093 & -0.43 & 0.28 \\
\hline pRFD 50ms & $\begin{array}{c}-853.3 \\
(-2345 \\
638.6)\end{array}$ & $\begin{array}{c}0.65 \\
(0.20, \\
0.88)\end{array}$ & $\begin{array}{c}23.57 \\
(16.69 \\
41.65)\end{array}$ & $\begin{array}{c}1661 \\
(1548, \\
1774)\end{array}$ & 4605 & -0.38 & 0.32 \\
\hline
\end{tabular}

Abbreviations: $\mathrm{ICC}=$ intraclass correlation coefficient; $\mathrm{CV} \%=$ coefficient of variation; $\mathrm{SEM}=$ standard error of measurement; $\mathrm{SDD}=$ smallest detectible difference; $\mathrm{CI}=$ confidence interval; TTPF = time to peak force $(\mathrm{ms})$; 
pRFD $=$ instantaneous RFD. Peak force measured in newtons (N), RFD measured in N/s. Numerical values presented after RFD represent pre-set time epochs. 
Table 3. Reliability statistics for ISqT ${ }^{\exp }$ test at $100^{\circ}$ knee flexion

\begin{tabular}{|c|c|c|c|c|c|c|c|}
\hline & $\begin{array}{c}\text { Change in } \\
\text { mean } \\
(90 \% \mathrm{CI})\end{array}$ & $\begin{array}{c}\text { ICC } \\
(90 \% \mathrm{CI})\end{array}$ & $\begin{array}{c}\text { CV\% } \\
(90 \% \mathrm{CI})\end{array}$ & $\begin{array}{c}\text { SEM } \\
(90 \% \mathrm{CI})\end{array}$ & SDD & $d$ & $p$ \\
\hline Peak Force & $\begin{array}{c}-106.4 \\
(-212.6,- \\
0.30)\end{array}$ & $\begin{array}{c}0.87 \\
(0.63, \\
0.96)\end{array}$ & $\begin{array}{c}8.53 \\
(6.15, \\
14.41)\end{array}$ & $\begin{array}{c}114.4 \\
(84.71 \\
144.0)\end{array}$ & 317.0 & -0.37 & 0.10 \\
\hline TTPF & $\begin{array}{c}0.029 \\
(-0.020 \\
0.079)\end{array}$ & $\begin{array}{l}0.86 \\
(0.63, \\
0.96)\end{array}$ & $\begin{array}{l}11.25 \\
(8.08, \\
19.17)\end{array}$ & $\begin{array}{c}0.053 \\
(-0.586 \\
0.693)\end{array}$ & 0.148 & 0.22 & 0.30 \\
\hline RFD 0-30ms & $\begin{array}{c}-296.6 \\
(-821.5 \\
228.3) \\
-632.5\end{array}$ & $\begin{array}{c}0.63 \\
(0.16, \\
0.87) \\
0.67\end{array}$ & $\begin{array}{c}65.94 \\
(44.68, \\
130.1) \\
51.13\end{array}$ & $\begin{array}{c}593.2 \\
(525.7 \\
660.7) \\
1072\end{array}$ & 1644 & -0.40 & 0.33 \\
\hline RFD $0-50 \mathrm{~ms}$ & $\begin{array}{c}(-1585 \\
320.0)\end{array}$ & $\begin{array}{l}(0.23, \\
0.88)\end{array}$ & $\begin{array}{l}(35.15 \\
97.28)\end{array}$ & $\begin{array}{c}(981.0 \\
1162)\end{array}$ & 2971 & -0.43 & 0.25 \\
\hline RFD $0-90 \mathrm{~ms}$ & $\begin{array}{c}-706.5 \\
(-1713 \\
299.8)\end{array}$ & $\begin{array}{c}0.65 \\
(0.20, \\
0.88)\end{array}$ & $\begin{array}{c}24.42 \\
(17.28 \\
43.25)\end{array}$ & $\begin{array}{l}1134 \\
(1040, \\
1227)\end{array}$ & 3143 & -0.47 & 0.23 \\
\hline $\begin{array}{l}\text { RFD 0- } \\
100 \mathrm{~ms}\end{array}$ & $\begin{array}{c}-632.0 \\
(-1535 \\
271.3)\end{array}$ & $\begin{array}{c}0.67 \\
(0.23, \\
0.88)\end{array}$ & $\begin{array}{c}21.68 \\
(15.39 \\
38.11)\end{array}$ & $\begin{array}{c}1009 \\
(920.8 \\
1097)\end{array}$ & 2796 & -0.45 & 0.23 \\
\hline $\begin{array}{c}\text { RFD 0- } \\
150 \mathrm{~ms}\end{array}$ & $\begin{array}{c}-420.2 \\
(-930.6 \\
90.3)\end{array}$ & $\begin{array}{c}0.83 \\
(0.55, \\
0.94)\end{array}$ & $\begin{array}{l}11.51 \\
(8.27 \\
19.63)\end{array}$ & $\begin{array}{c}549.9 \\
(484.9 \\
615.0)\end{array}$ & 1524 & -0.35 & 0.17 \\
\hline $\begin{array}{l}\text { RFD 0- } \\
200 \mathrm{~ms}\end{array}$ & $\begin{array}{c}-260.3 \\
(-566.0 \\
45.4)\end{array}$ & $\begin{array}{c}0.92 \\
(0.77 \\
0.97)\end{array}$ & $\begin{array}{c}7.00 \\
(5.06 \\
11.78)\end{array}$ & $\begin{array}{c}323.2 \\
(273.4 \\
373.1)\end{array}$ & 895.9 & -0.24 & 0.15 \\
\hline $\begin{array}{l}\text { RFD 0- } \\
250 \mathrm{~ms}\end{array}$ & $\begin{array}{c}-246.6 \\
(-484.3,- \\
9.0)\end{array}$ & $\begin{array}{c}0.94 \\
(0.81, \\
0.98)\end{array}$ & $\begin{array}{c}6.18 \\
(4.47 \\
10.36)\end{array}$ & $\begin{array}{c}249.8 \\
(206.0 \\
293.6)\end{array}$ & 692.5 & -0.26 & 0.09 \\
\hline $\begin{array}{c}\text { Average } \\
\text { RFD }\end{array}$ & $\begin{array}{c}-368.4 \\
(-601.9,- \\
134.9)\end{array}$ & $\begin{array}{c}0.93 \\
(0.80, \\
0.98)\end{array}$ & $\begin{array}{l}10.48 \\
(7.54, \\
17.82)\end{array}$ & $\begin{array}{c}247.1 \\
(203.5 \\
290.6)\end{array}$ & 684.8 & -0.41 & 0.02 \\
\hline pRFD $1 \mathrm{~ms}$ & $\begin{array}{c}4.66 \\
(-944.9 \\
954.2)\end{array}$ & $\begin{array}{c}0.85 \\
(0.59, \\
0.95)\end{array}$ & $\begin{array}{l}10.54 \\
(7.58, \\
17.92)\end{array}$ & $\begin{array}{c}1023 \\
(934.1 \\
1111)\end{array}$ & 2835 & 0.00 & 0.99 \\
\hline pRFD $2 \mathrm{~ms}$ & $\begin{array}{c}-32.66 \\
(-1013 \\
947.9)\end{array}$ & $\begin{array}{c}0.84 \\
(0.57, \\
0.95)\end{array}$ & $\begin{array}{l}11.04 \\
(7.94, \\
18.81)\end{array}$ & $\begin{array}{c}1056 \\
(966.2 \\
1146)\end{array}$ & 2928 & -0.01 & 0.95 \\
\hline pRFD 5ms & $\begin{array}{c}51.30 \\
(-955.4 \\
1058)\end{array}$ & $\begin{array}{c}0.84 \\
(0.56, \\
0.95)\end{array}$ & $\begin{array}{l}11.59 \\
(8.33, \\
19.78)\end{array}$ & $\begin{array}{c}1085 \\
(993.8, \\
1176)\end{array}$ & 3008 & 0.02 & 0.93 \\
\hline pRFD 10ms & $\begin{array}{c}25.75 \\
(-976.5 \\
1028)\end{array}$ & $\begin{array}{c}0.84 \\
(0.56 \\
0.95)\end{array}$ & $\begin{array}{l}11.67 \\
(8.38, \\
19.91)\end{array}$ & $\begin{array}{c}1080 \\
(988.9 \\
1171)\end{array}$ & 2994 & 0.01 & 0.96 \\
\hline pRFD 20ms & $\begin{array}{c}23.74 \\
(-962.2 \\
1010)\end{array}$ & $\begin{array}{c}0.83 \\
(0.55 \\
0.94)\end{array}$ & $\begin{array}{l}11.75 \\
(8.44, \\
20.05)\end{array}$ & $\begin{array}{c}1063 \\
(972.3 \\
1153)\end{array}$ & 2946 & 0.01 & 0.97 \\
\hline pRFD 30ms & $\begin{array}{c}17.47 \\
(-932.1 \\
967.0)\end{array}$ & $\begin{array}{c}0.83 \\
(0.54, \\
0.94)\end{array}$ & $\begin{array}{l}11.61 \\
(8.34, \\
19.81)\end{array}$ & $\begin{array}{c}1024 \\
(935.2 \\
1113)\end{array}$ & 2838 & 0.01 & 0.97 \\
\hline pRFD 50ms & $\begin{array}{c}21.12 \\
(-823.9 \\
866.1)\end{array}$ & $\begin{array}{c}0.82 \\
(0.52, \\
0.94)\end{array}$ & $\begin{array}{l}11.08 \\
(7.97, \\
18.87) \\
\end{array}$ & $\begin{array}{c}910.3 \\
(826.6, \\
993.9)\end{array}$ & 2523 & 0.01 & 0.96 \\
\hline
\end{tabular}

Abbreviations: ICC $=$ intraclass correlation coefficient; $\mathrm{CV} \%=$ coefficient of variation; $\mathrm{SEM}=$ standard error of measurement; $\mathrm{SDD}=$ smallest detectible difference; $\mathrm{CI}=$ confidence interval; TTPF = time to peak force $(\mathrm{ms})$; 
pRFD $=$ instantaneous RFD. Peak force measured in newtons (N), RFD measured in N/s. Numerical values presented after RFD represent pre-set time epochs. 
Table 4. Reliability statistics for ISqT ${ }^{\exp }$ test at $125^{\circ}$ knee flexion

\begin{tabular}{|c|c|c|c|c|c|c|c|}
\hline & $\begin{array}{c}\text { Change in } \\
\text { mean } \\
(90 \% \mathrm{CI})\end{array}$ & $\begin{array}{c}\text { ICC } \\
(90 \% \mathrm{CI})\end{array}$ & $\begin{array}{c}\text { CV\% } \\
(90 \% \mathrm{CI})\end{array}$ & $\begin{array}{c}\text { SEM } \\
(90 \% \mathrm{CI})\end{array}$ & SDD & $d$ & $p$ \\
\hline & -102.4 & 0.79 & 7.29 & 152.7 & & & \\
\hline Peak Force & $\begin{array}{c}(-241.5 \\
36.77)\end{array}$ & $\begin{array}{c}(0.46, \\
0.93)\end{array}$ & $\begin{array}{l}(5.26, \\
12.27)\end{array}$ & $\begin{array}{c}(118.4 \\
186.9)\end{array}$ & 423.2 & -0.35 & 0.21 \\
\hline & -0.080 & 0.74 & 23.96 & 0.077 & & & \\
\hline TTPF & $\begin{array}{c}(-0.150,- \\
0.011)\end{array}$ & $\begin{array}{l}(0.36, \\
0.91)\end{array}$ & $\begin{array}{l}(16.96 \\
42.39)\end{array}$ & $\begin{array}{c}(-0.694 \\
0.849)\end{array}$ & 0.215 & -0.63 & 0.06 \\
\hline & -168.0 & 0.63 & 34.50 & 594.1 & & & \\
\hline RFD 0-30ms & $\begin{array}{c}(-692.8 \\
356.7)\end{array}$ & $\begin{array}{l}(0.17, \\
0.87)\end{array}$ & $\begin{array}{l}(24.13, \\
62.84)\end{array}$ & $\begin{array}{l}(526.6 \\
661.7)\end{array}$ & 1647 & -0.22 & 0.57 \\
\hline & -395.1 & 0.77 & 28.28 & 888.4 & & & \\
\hline RFD $0-50 \mathrm{~ms}$ & $\begin{array}{l}(-1200 \\
409.4)\end{array}$ & $\begin{array}{l}(0.42, \\
0.92)\end{array}$ & $\begin{array}{c}(19.92 \\
50.64)\end{array}$ & $\begin{array}{c}(805.8, \\
971.0)\end{array}$ & 2463 & -0.25 & 0.39 \\
\hline RFD $0-90 \mathrm{~ms}$ & $\begin{array}{c}-540.3 \\
(-1199 \\
117.9)\end{array}$ & $\begin{array}{c}0.90 \\
(0.71 \\
0.97)\end{array}$ & $\begin{array}{l}13.00 \\
(9.32 \\
22.27)\end{array}$ & $\begin{array}{c}703.5 \\
(630.0 \\
777.0)\end{array}$ & 1950 & -0.26 & 0.17 \\
\hline $\begin{array}{l}\text { RFD 0- } \\
100 \mathrm{~ms}\end{array}$ & $\begin{array}{l}-491.2 \\
(-1071 \\
88.36)\end{array}$ & $\begin{array}{l}0.91 \\
(0.75 \\
0.97)\end{array}$ & $\begin{array}{l}10.68 \\
(7.68 \\
18.17)\end{array}$ & $\begin{array}{c}616.0 \\
(547.2 \\
684.8)\end{array}$ & 1707 & -0.25 & 0.15 \\
\hline $\begin{array}{l}\text { RFD 0- } \\
150 \mathrm{~ms}\end{array}$ & $\begin{array}{c}-421.0 \\
(-816.6,- \\
25.47)\end{array}$ & $\begin{array}{c}0.95 \\
(0.85 \\
0.98)\end{array}$ & $\begin{array}{c}5.83 \\
(4.22,9.77)\end{array}$ & $\begin{array}{c}414.7 \\
(358.2, \\
471.1)\end{array}$ & 1149 & -0.23 & 0.08 \\
\hline $\begin{array}{l}\text { RFD 0- } \\
200 \mathrm{~ms}\end{array}$ & $\begin{array}{c}-298.2 \\
(-547.0,- \\
49.45)\end{array}$ & $\begin{array}{l}0.97 \\
(0.92 \\
0.99)\end{array}$ & $\begin{array}{c}4.13 \\
(3.00,6.88)\end{array}$ & $\begin{array}{c}259.1 \\
(214.5 \\
303.7)\end{array}$ & 718.2 & -0.19 & 0.056 \\
\hline $\begin{array}{l}\text { RFD 0- } \\
250 \mathrm{~ms}\end{array}$ & $\begin{array}{c}-338.6 \\
(-645.6,- \\
31.61)\end{array}$ & $\begin{array}{c}0.94 \\
(0.82 \\
0.98)\end{array}$ & $\begin{array}{c}5.20 \\
(3.76,8.69)\end{array}$ & $\begin{array}{c}323.6 \\
(273.7 \\
373.5)\end{array}$ & 896.9 & -0.27 & 0.07 \\
\hline $\begin{array}{c}\text { Average } \\
\text { RFD }\end{array}$ & $\begin{array}{c}795.8 \\
(-215.8 \\
1807)\end{array}$ & $\begin{array}{l}0.60 \\
(0.11 \\
0.85)\end{array}$ & $\begin{array}{c}22.48 \\
(15.94 \\
39.60)\end{array}$ & $\begin{array}{c}1125 \\
(1032 \\
1218)\end{array}$ & 3119 & 0.59 & 0.18 \\
\hline pRFD $1 \mathrm{~ms}$ & $\begin{array}{c}51.51 \\
(-936.1 \\
1039)\end{array}$ & $\begin{array}{c}0.91 \\
(0.74, \\
0.97)\end{array}$ & $\begin{array}{l}10.09 \\
(7.26 \\
17.13)\end{array}$ & $\begin{array}{c}1052 \\
(962.2 \\
1142)\end{array}$ & 2916 & 0.02 & 0.93 \\
\hline pRFD $2 \mathrm{~ms}$ & $\begin{array}{c}73.02 \\
(-900.5 \\
1047)\end{array}$ & $\begin{array}{l}0.91 \\
(0.75 \\
0.97)\end{array}$ & $\begin{array}{l}10.05 \\
(7.24, \\
17.07)\end{array}$ & $\begin{array}{c}1036 \\
(946.5 \\
1125)\end{array}$ & 2871 & 0.02 & 0.89 \\
\hline pRFD 5ms & $\begin{array}{c}90.58 \\
(-940.1 \\
1121)\end{array}$ & $\begin{array}{l}0.91 \\
(0.73 \\
0.97)\end{array}$ & $\begin{array}{l}11.08 \\
(7.97, \\
18.87)\end{array}$ & $\begin{array}{l}1099 \\
(1007, \\
1191)\end{array}$ & 3047 & 0.03 & 0.88 \\
\hline & 37.24 & 0.90 & 11.29 & 1111 & & & \\
\hline pRFD 10ms & $\begin{array}{c}(-1003, \\
1078)\end{array}$ & $\begin{array}{l}(0.72, \\
0.97)\end{array}$ & $\begin{array}{l}(8.11, \\
19.24)\end{array}$ & $\begin{array}{l}(1019, \\
1204)\end{array}$ & 3080 & 0.01 & 0.95 \\
\hline pRFD 20ms & $\begin{array}{c}30.41 \\
(-981.3 \\
1042)\end{array}$ & $\begin{array}{l}0.90 \\
(0.72 \\
0.97)\end{array}$ & $\begin{array}{l}11.11 \\
(7.99 \\
18.93)\end{array}$ & $\begin{array}{c}1081 \\
(989.6, \\
1172)\end{array}$ & 2996 & 0.01 & 0.96 \\
\hline pRFD 30ms & $\begin{array}{c}8.05 \\
(-949.1 \\
965.2)\end{array}$ & $\begin{array}{c}0.90 \\
(0.71, \\
0.97)\end{array}$ & $\begin{array}{l}10.75 \\
(7.73, \\
18.29)\end{array}$ & $\begin{array}{c}1023 \\
(934.0 \\
1111)\end{array}$ & 2835 & 0.00 & 0.99 \\
\hline pRFD 50ms & $\begin{array}{c}-43.52 \\
(-859.5 \\
772.4)\end{array}$ & $\begin{array}{c}0.90 \\
(0.71, \\
0.97)\end{array}$ & $\begin{array}{c}9.66 \\
(6.95, \\
16.38) \\
\end{array}$ & $\begin{array}{r}871.4 \\
(789.5 \\
953.2)\end{array}$ & 2415 & -0.02 & 0.92 \\
\hline
\end{tabular}

Abbreviations: ICC $=$ intraclass correlation coefficient; $\mathrm{CV} \%=$ coefficient of variation; $\mathrm{SEM}=$ standard error of measurement; $\mathrm{SDD}=$ smallest detectible difference; $\mathrm{CI}=$ confidence interval; TTPF = time to peak force $(\mathrm{ms})$; 
pRFD $=$ instantaneous RFD. Peak force measured in newtons (N), RFD measured in N/s. Numerical values presented after RFD represent pre-set time epochs. 
Table 5. Mean results by test protocol and test angle

\begin{tabular}{|c|c|c|c|c|}
\hline & $\begin{array}{l}\mathrm{ISqT}^{\text {peak }} 100 \\
(\text { Mean } \pm \mathrm{SD})\end{array}$ & $\begin{array}{l}\mathrm{ISqT}^{\text {peak }} 125 \\
(\mathrm{Mean} \pm \mathrm{SD})\end{array}$ & $\begin{array}{c}\mathrm{ISqT}^{\exp } 100 \\
(\text { Mean } \pm \mathrm{SD})\end{array}$ & $\begin{array}{c}\mathrm{ISqT}^{\exp } 125 \\
(\text { Mean } \pm \mathrm{SD})\end{array}$ \\
\hline Peak Force & $2013 \pm 251.7$ & $2904 \pm 408.8$ & $1791 \pm 315.5$ & $2393 \pm 337.0$ \\
\hline TTPF & $1.78 \pm 0.43$ & $2.03 \pm 0.30$ & $0.53 \pm 0.14$ & $0.51 \pm 0.16$ \\
\hline RFD $0-30 \mathrm{~ms}$ & $1261 \pm 529$ & $1787 \pm 1015$ & $1834 \pm 974.1$ & $2467 \pm 1010$ \\
\hline RFD $0-50 \mathrm{~ms}$ & $1950 \pm 937.6$ & $2829 \pm 1781$ & $3500 \pm 1876$ & $4549 \pm 1974$ \\
\hline RFD 0-90ms & $3122 \pm 1652$ & $4349 \pm 2279$ & $5824 \pm 1921$ & $6963 \pm 2241$ \\
\hline RFD 0-100ms & $3315 \pm 1711$ & $4581 \pm 2229$ & $6059 \pm 1762$ & $7192 \pm 2112$ \\
\hline RFD 0-150ms & $3890 \pm 1709$ & $5548 \pm 2165$ & $6445 \pm 1352$ & $7964 \pm 1867$ \\
\hline RFD 0-200ms & $3982 \pm 1506$ & $5833 \pm 1980$ & $6119 \pm 1145$ & $7831 \pm 1616$ \\
\hline RFD 0-250ms & $3828 \pm 1237$ & $5577 \pm 1662$ & $5551 \pm 984$ & $7276 \pm 1342$ \\
\hline Average RFD & $1034 \pm 337.8$ & $1302 \pm 221.3$ & $3360 \pm 939.5$ & $5103 \pm 1870$ \\
\hline pRFD $1 \mathrm{~ms}$ & $7068 \pm 1819$ & $9422 \pm 3190$ & $11420 \pm 2626$ & $13024 \pm 3401$ \\
\hline pRFD 2ms & $6875 \pm 1808$ & $9244 \pm 3223$ & $11250 \pm 2657$ & $12817 \pm 3425$ \\
\hline pRFD 5ms & $6664 \pm 1784$ & $9008 \pm 3228$ & $11030 \pm 2680$ & $12594 \pm 3467$ \\
\hline pRFD $10 \mathrm{~ms}$ & $6580 \pm 1774$ & $8934 \pm 3223$ & $10937 \pm 2671$ & $12494 \pm 3432$ \\
\hline pRFD 20ms & $6479 \pm 1748$ & $8815 \pm 3169$ & $10757 \pm 2591$ & $12287 \pm 3313$ \\
\hline pRFD $30 \mathrm{~ms}$ & $6377 \pm 1713$ & $8667 \pm 3068$ & $10495 \pm 2462$ & $11994 \pm 3109$ \\
\hline pRFD 50ms & $6171 \pm 1630$ & $8316 \pm 2826$ & $9844 \pm 2134$ & $11266 \pm 2617$ \\
\hline
\end{tabular}

Abbreviations: TTPF $=$ time to peak force $(\mathrm{ms}) ; \mathrm{pRFD}=$ instantaneous RFD. Peak force measured in newtons $(\mathrm{N})$, RFD measured in N/s. Numerical values presented after RFD represent pre-set time epochs. 
Table 6. Comparison of peak force values between test angle and test protocol.

\begin{tabular}{|c|c|c|c|c|c|c|c|}
\hline & \multirow{2}{*}{$\begin{array}{c}\text { Mean } \\
\text { difference }\end{array}$} & \multicolumn{2}{|c|}{$\begin{array}{l}95 \% \text { confidence interval } \\
\text { of the difference }\end{array}$} & \multirow{2}{*}{$p$ value } & \multirow{2}{*}{ Effect size } & \multicolumn{2}{|c|}{$\begin{array}{l}95 \% \text { confidence } \\
\text { interval of the effect }\end{array}$} \\
\hline & & Lower & Upper & & & Lower & Upper \\
\hline $\begin{array}{c}\text { ISqT }^{\text {peak }} 100 \text { to } \mathrm{ISqT}^{\text {peak }} \\
125\end{array}$ & -907.9 & -1213 & -602.6 & .000 & -2.20 & -3.75 & -1.38 \\
\hline $\mathrm{ISqT}^{\exp } 100$ to ISqT $\mathrm{T}^{\exp } 125$ & -633.1 & -875.9 & -390.2 & .000 & -1.75 & -2.78 & -0.72 \\
\hline ISqT $^{\text {peak }} 100$ to ISqT ${ }^{\exp } 100$ & 167.4 & 23.67 & 311.1 & .027 & 0.50 & -0.34 & 1.44 \\
\hline ISqT $^{\text {peak }} 125$ to ISqT ${ }^{\exp } 125$ & 442.2 & 254.2 & 630.2 & .000 & 1.22 & -0.68 & 1.08 \\
\hline
\end{tabular}


Table 7. Comparison of RFD 200ms values between test angle and test protocol.

\begin{tabular}{|c|c|c|c|c|c|c|c|}
\hline & \multirow{2}{*}{$\begin{array}{c}\text { Mean } \\
\text { difference }\end{array}$} & \multicolumn{2}{|c|}{$\begin{array}{c}95 \% \text { confidence interval } \\
\text { of the difference }\end{array}$} & \multirow{2}{*}{$\begin{array}{c}p \\
\text { value }\end{array}$} & \multirow{2}{*}{$\begin{array}{l}\text { Effect } \\
\text { size }\end{array}$} & \multicolumn{2}{|c|}{$\begin{array}{c}95 \% \text { confidence } \\
\text { interval of the } \\
\text { effect }\end{array}$} \\
\hline & & Lower & Upper & & & Lower & Upper \\
\hline ISqT $^{\text {peak }} 100$ to ISqT ${ }^{\text {peak }} 125$ & -1937 & -3086 & -787.6 & .004 & -0.82 & -1.89 & -0.03 \\
\hline ISqT $^{\exp } 100$ to ISqT ${ }^{\exp } 125$ & -1880 & -2653 & -1108 & .000 & -1.21 & -2.34 & -0.39 \\
\hline ISqT $^{\text {peak }} 100$ to ISqT $^{\exp } 100$ & -2072 & -3120 & -1024 & .002 & -1.99 & -2.64 & -0.62 \\
\hline ISqT $^{\text {peak }} 125$ to ISqT ${ }^{\exp } 125$ & -2015 & -3365 & -666.3 & .008 & -1.30 & -1.89 & -0.04 \\
\hline
\end{tabular}




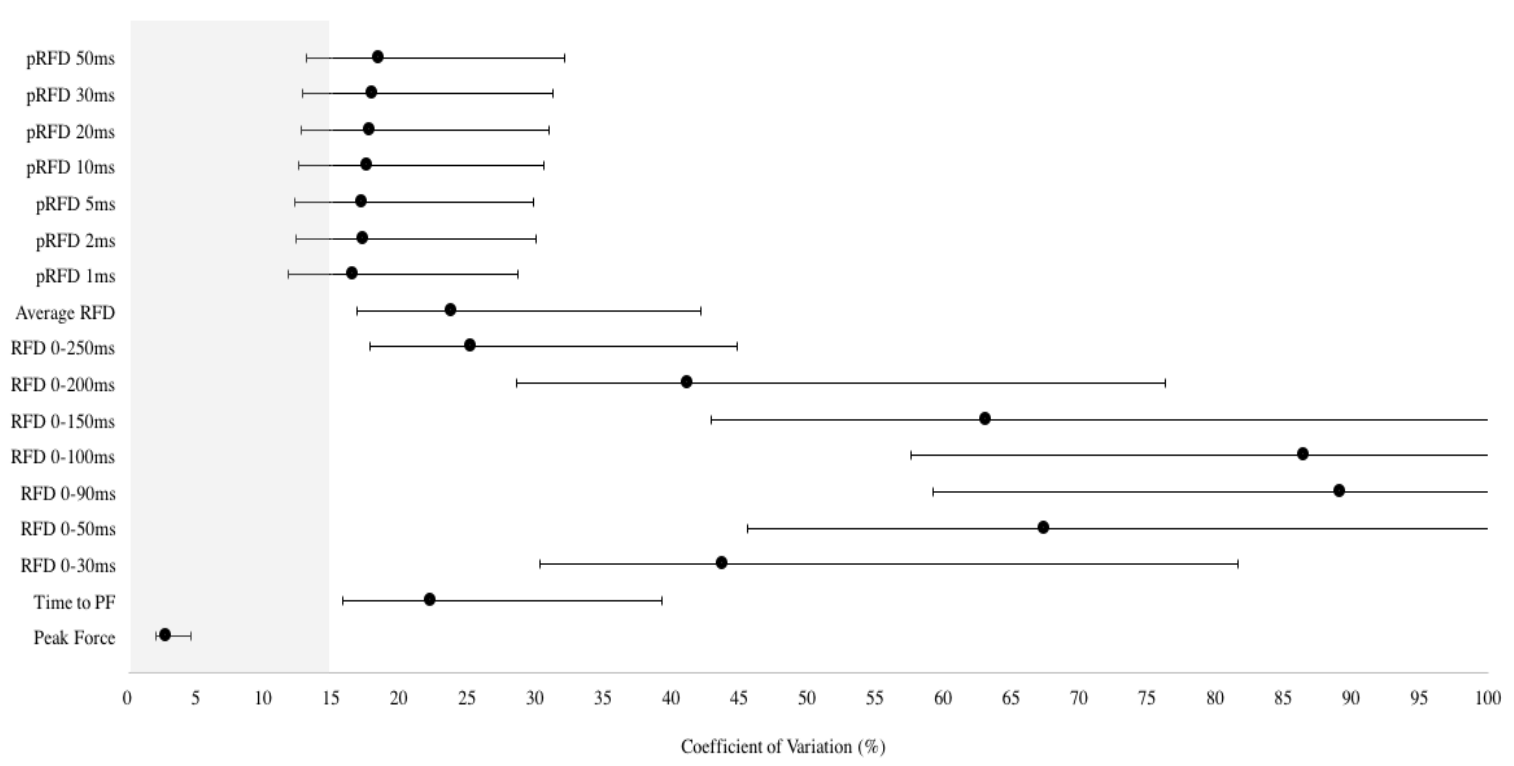

Figure 1. Coefficient of variation and $90 \% \mathrm{CI}$ for the isometric peak force test at $100^{\circ}$

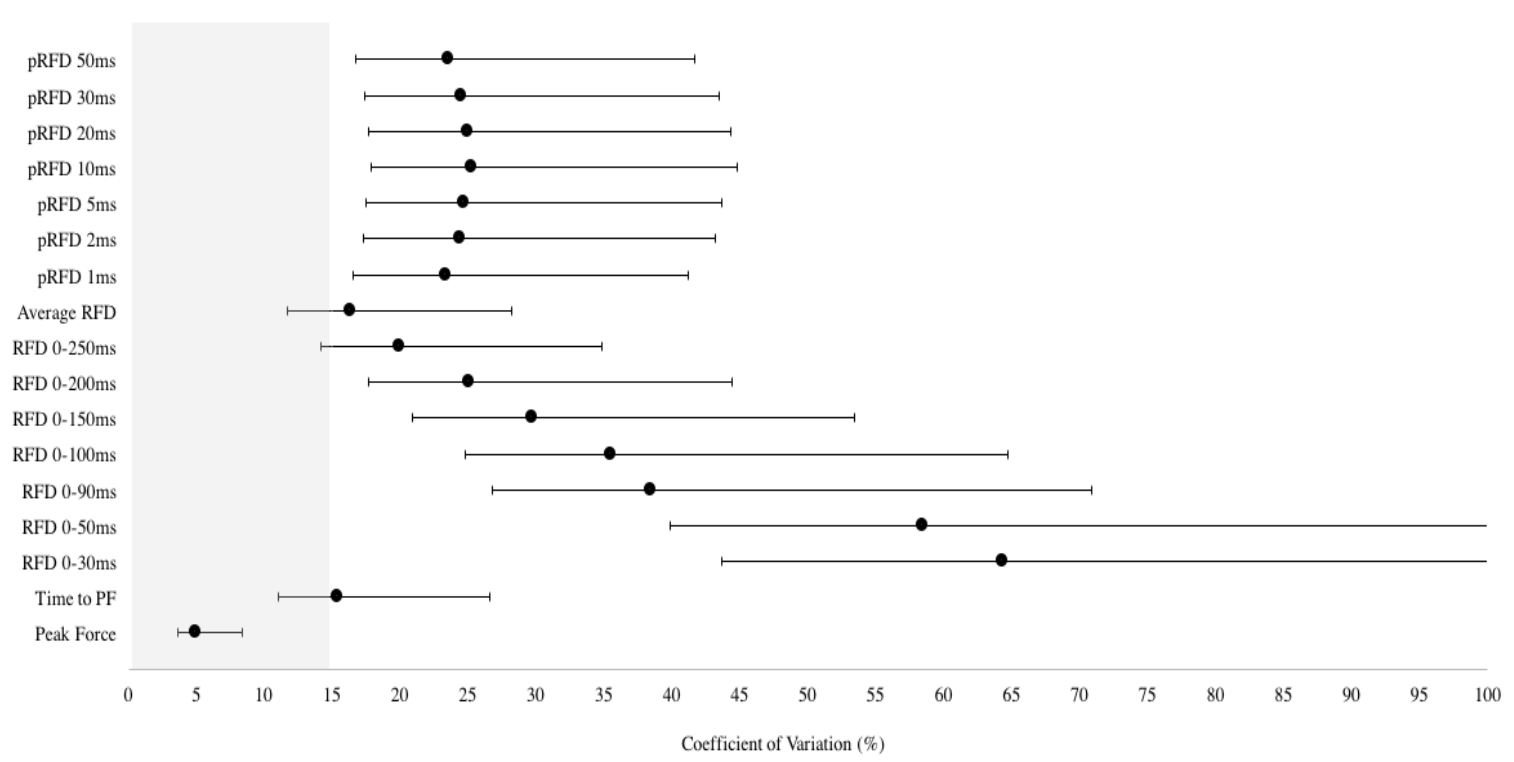

Figure 2. Coefficient of variation and $90 \% \mathrm{CI}$ for the isometric peak force test at $125^{\circ}$ 


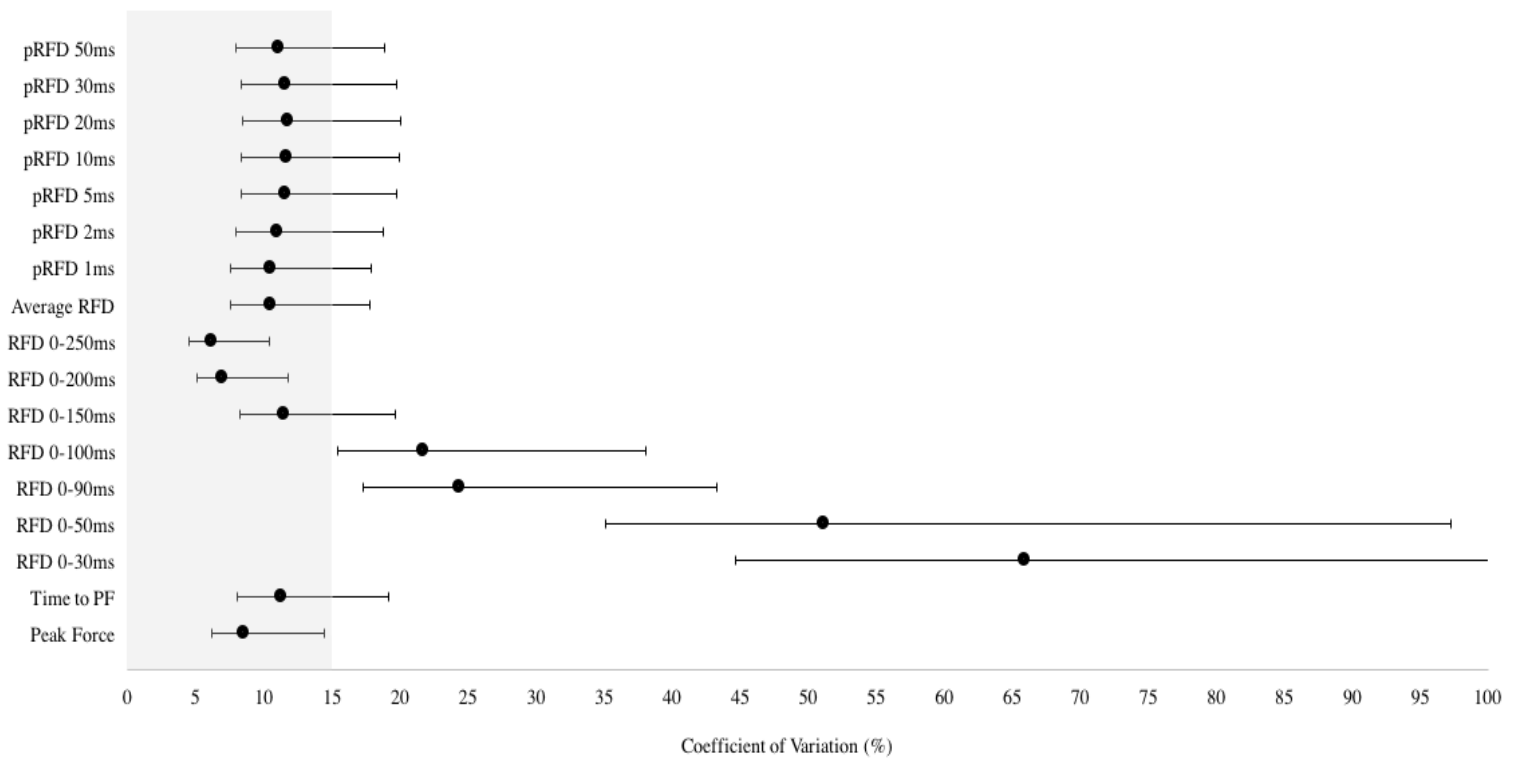

Figure 3. Coefficient of variation and $90 \% \mathrm{CI}$ for the isometric explosive force test at $100^{\circ}$

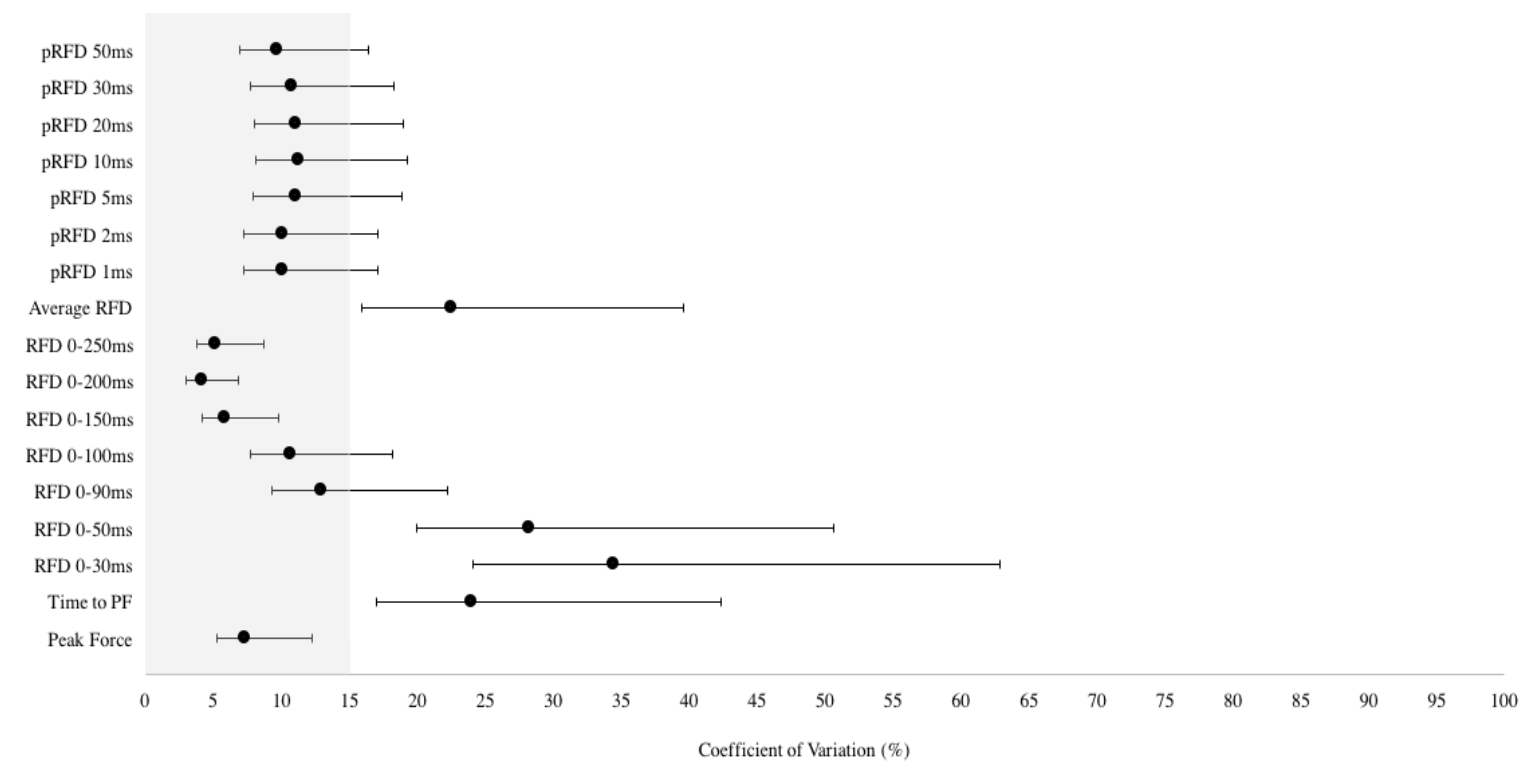

Figure 4. Coefficient of variation and $90 \% \mathrm{CI}$ for the isometric explosive force test at $125^{\circ}$ 


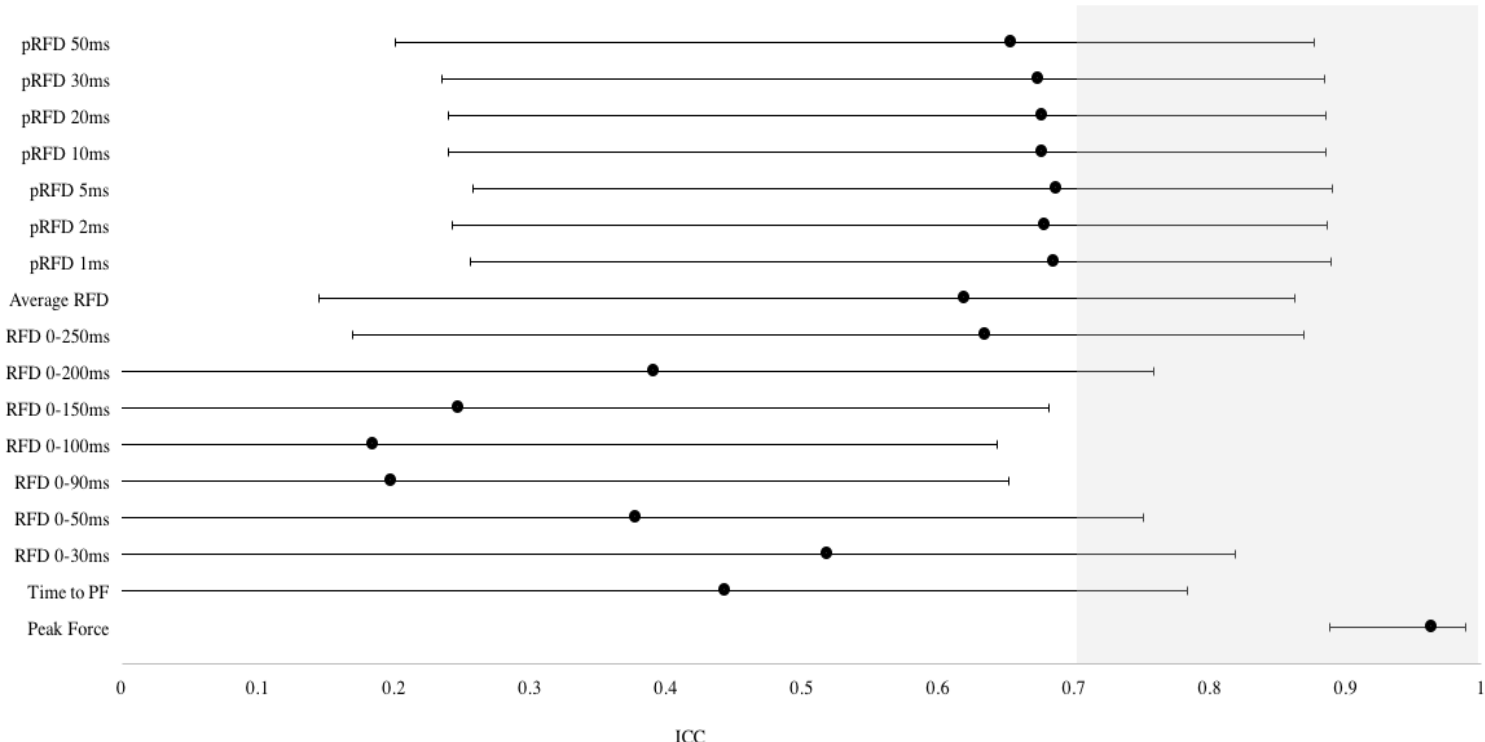

Figure 5. Intraclass coefficient and $90 \% \mathrm{CI}$ for the isometric peak force test at $100^{\circ}$

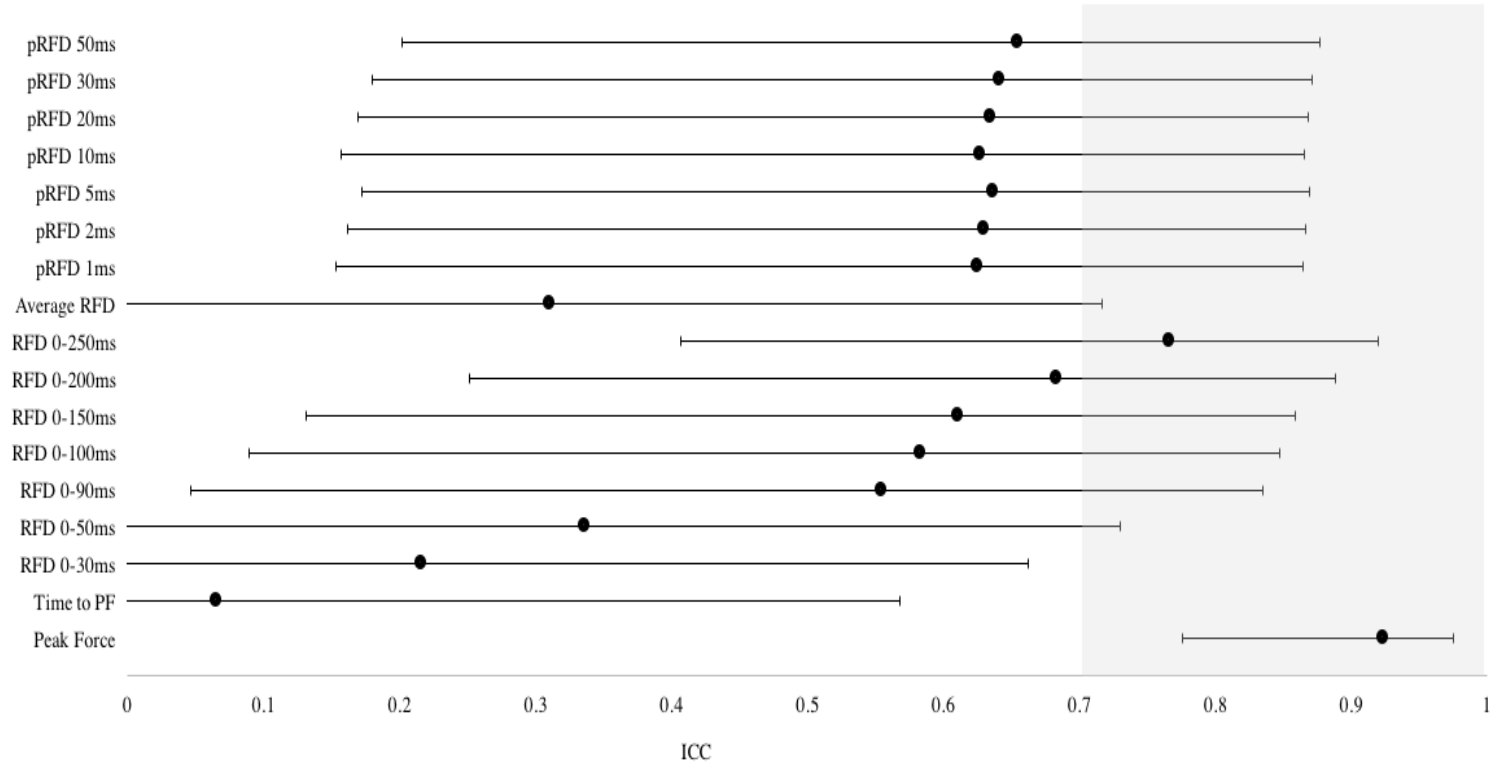

Figure 6. Intraclass coefficient and $90 \% \mathrm{CI}$ for the isometric peak force test at $125^{\circ}$ 


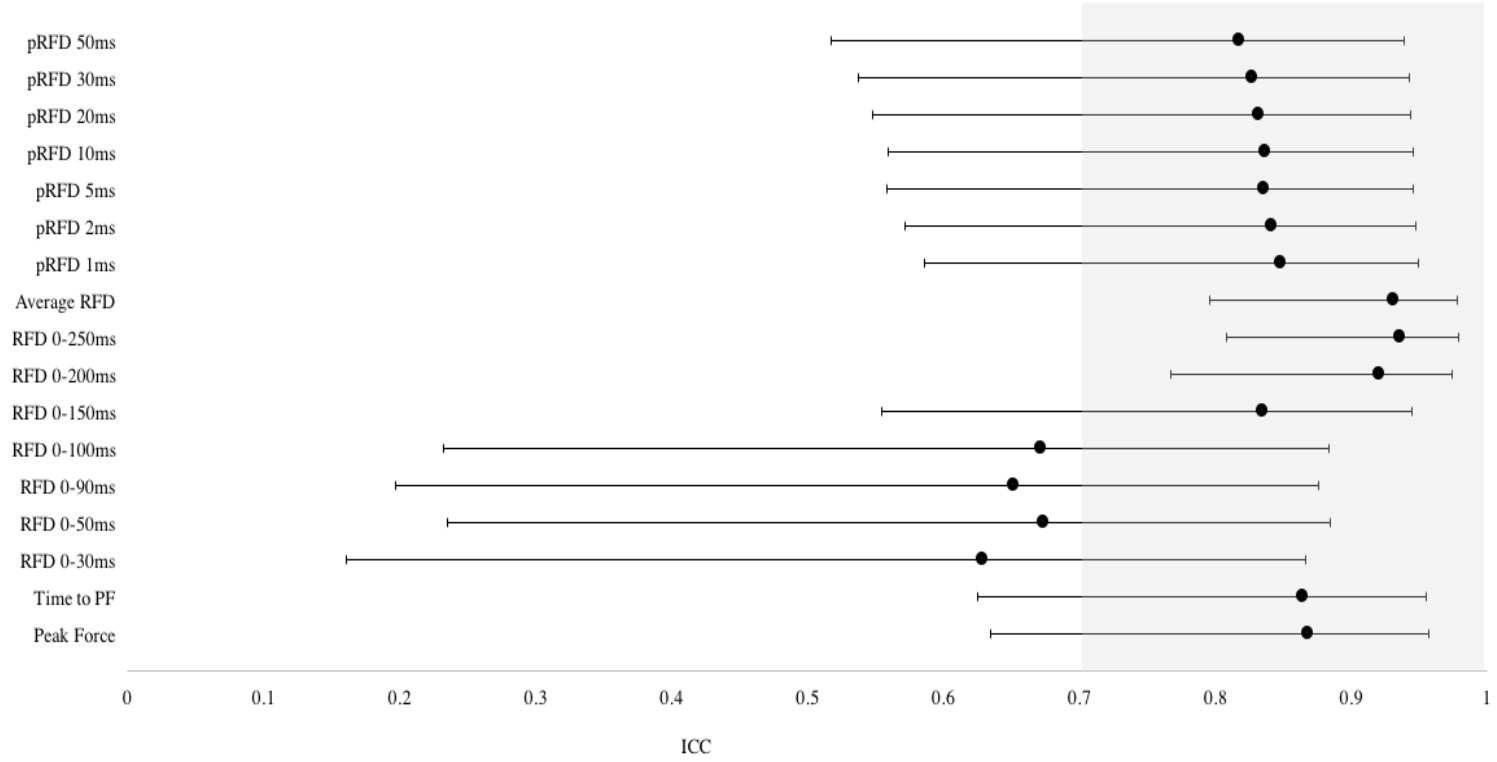

Figure 7. Intraclass coefficient and $90 \% \mathrm{CI}$ for the isometric explosive force test at $100^{\circ}$

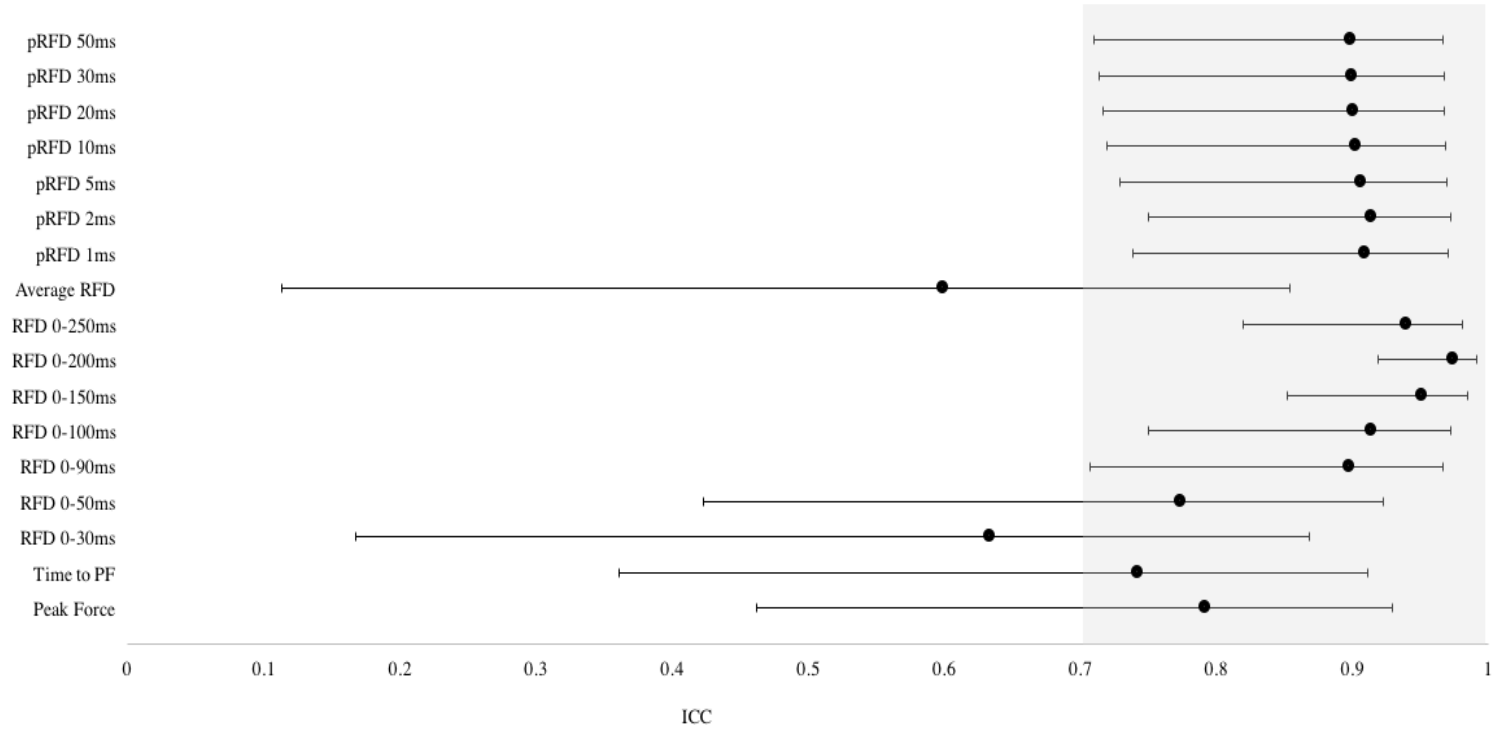

Figure 8. Intraclass coefficient and 90\% CI for the isometric explosive force test at $125^{\circ}$ 